\title{
Dynamics and interplay of nuclear architecture, genome organization, and gene expression
}

\author{
Robert Schneider and Rudolf Grosschedl ${ }^{1}$ \\ Max Planck Institute of Immunobiology, 79108 Freiburg, Germany
}

The organization of the genome in the nucleus of a eukaryotic cell is fairly complex and dynamic. Various features of the nuclear architecture, including compartmentalization of molecular machines and the spatial arrangement of genomic sequences, help to carry out and regulate nuclear processes, such as DNA replication, DNA repair, gene transcription, RNA processing, and mRNA transport. Compartmentalized multiprotein complexes undergo extensive modifications or exchange of protein subunits, allowing for an exquisite dynamics of structural components and functional processes of the nucleus. The architecture of the interphase nucleus is linked to the spatial arrangement of genes and gene clusters, the structure of chromatin, and the accessibility of regulatory DNA elements. In this review, we discuss recent studies that have provided exciting insight into the interplay between nuclear architecture, genome organization, and gene expression.

One of the striking features of the eukaryotic cell nucleus, which carries and reads the genetic information, is its functional and structural complexity. The human genome, containing some 35,000 genes and 3.2 billion base pairs of DNA, is compacted 400,000-fold to fit within a nuclear volume of $\sim 1000 \mu \mathrm{m}^{3}$. The packing of DNA into chromatin is an extremely efficient way of storing the DNA within the nucleus. However, the genetic information has to become accessible for DNAdependent processes such as transcription, DNA repair, and replication. Most importantly, this accessibility is regulated, as not all regions of the genome are active at a given time during the cell cycle. In recent years, increasing evidence has been accumulated suggesting that cisand trans-acting regulatory DNA sequences may not be the only determinants of gene expression, but that DNA transactions also depend on the genomic position of genes, the subnuclear localization of DNA sequences, and a complex interplay of the genome with specific features of nuclear architecture.

[Keywords: Nuclear organization; chromatin; gene localization; chromosomal interactions]

${ }^{1}$ Corresponding author.

E-MAIL grosschedl@immunbio.mpg.de; FAX 49-761-5108798.

Article is online at http://www.genesdev.org/cgi/doi/10.1101/gad.1604607.

The nucleus is organized in specific compartments that include proteinaceous nuclear bodies, eukaryotic and heterochromatic chromatin domains, compartmentalized multiprotein complexes, and nuclear pores that allow for nucleocytoplasmic transport. The dynamic, temporal, and spatial organization of the eukaryotic cell nucleus emerges as a central determinant of genome function, and it is important to understand the relationship between nuclear architecture, genome organization, and gene expression. Recently, high-resolution techniques have permitted new insights into the nuclear architecture and its relationship to gene expression.

In this review, we focus on the dynamic organization of the genome into chromosome territories and chromatin domains. We also discuss the link of subnuclear gene positioning with gene expression and how intraand interchromosomal interactions may contribute to gene regulation.

Within the nucleus many proteinaceous nuclear bodies, such as PML bodies or Cajal bodies, have been described (for detailed review, see Spector 2003). These bodies have a nonrandom positioning relative to specific nuclear regions. Distinct functions have been attributed to the various nuclear bodies, but we are just beginning to understand the role of nuclear bodies in gene transcription, RNA processing, and DNA repair. An interesting feature of nuclear bodies is the involvement of post-transcriptional protein modifications, such as SUMOylation for PML bodies or arginine methylation for Cajal bodies, in their generation and/or maintenance (for review, see Seeler and Dejean 2003; Heun 2007).

\section{Chromatin domains}

In addition to the proteinaceous nuclear bodies, largescale chromatin domains exist that are mainly cytologically defined. In 1928, Heitz subdivided chromatinbased on its microscopic appearance-into heterochromatin and euchromatin (Heitz 1928). Euchromatin was correlated with the bulk of transcribed chromatin, which is in an "open" chromatin conformation. In contrast, heterochromatin was correlated with more condensed chromatin, which is enriched in inactive and silenced chromatin regions. Heterochromatin was considered to 
be transcriptionally inert. However, in the last few years it has become clear that this correlation of chromatin structure and gene function is limited. Recently, the Bickmore group (Gilbert et al. 2004) analyzed chromatin structure at a more global level. They fractionated chromatin into open, bulk, and closed chromatin fibers and assayed the distribution of gene density and activity in these chromatin fractions. Surprisingly, they found a link between chromatin structure and gene density, independent of the status of gene activity. Open chromatin fibers correlate with highest gene density, but not gene expression levels, whereas compact chromatin fibers generally have a low gene density, but can also contain active genes (Gilbert et al. 2004). The ability of genes to be activated is not necessarily lost when chromatin is packed into more compact fibers. Conversely, inactive genes close to active genes in an open chromatin environment can stay inactive. In these cases, it is not the location of a gene in heterochromatic or euchromatic chromatin domains that regulates gene activity, but rather, other factors such as covalent modifications of histones or DNA (Spector 2004).

\section{Transcription factories}

Microscopic analysis of sites of active transcription in HeLa cell nuclei, using Br-UTP incorporation, revealed a nonhomogeneous clustering of $\sim 10^{4}$ transcription sites, with 8000 sites representing RNA polymerase II clusters and the rest RNA polymerase III transcription sites (Pombo et al. 1999). The number of transcription sites varies in different cells. These sites of active transcription measure $\sim 80 \mathrm{~nm}$ in diameter, and they have been termed "transcription factories" (Jackson et al. 1998).

The textbook concept for a long time was that active genes recruit the transcription machinery, and it is the transcription machinery that relocates to the active genes. However, three-dimensional fluorescence in situ hybridization (3D-FISH), immunofluorescence, and chromosome conformation capture (3C) analysis, which detects close physical proximity between remote chromatin segments (Dekker 2006), provided new insights into the organization of transcription sites and raised questions about this dogma. Using a combination of these methods, the Fraser group (Osborne et al. 2004) showed that widely separated active genes can colocalize to these sites of active transcription. They demonstrated that genes are dynamically recruited to these sites of active transcription (not vice versa), and that most genes can move in and out of these sites, resulting in activation or abatement of their transcription (Osborne et al. 2004). Genes that are capable of high expression levels, such as $\beta$-globin, $\alpha$-globin, and immunoglobulin genes, seem to be constantly associated with "transcription factories" in cells that express these genes, whereas temporarily quiescent alleles are located away from the factories (Osborne et al. 2004). Transcriptional activation of highly expressed genes such as immediate early genes involves their relocalization to preassembled transcription sites (Osborne et al. 2007). These transcription sites may be maintained by flanking, ubiquitously expressed housekeeping genes (Zhou et al. 2006), or by locus control regions (Ragoczy et al. 2006).

According to the "transcription factory" model, RNA polymerase complexes, and transcription factors cluster and form a "cloud" of up to 20 DNA loops around the transcription factory (Cook 1999; Faro-Trindade and Cook 2006). The polymerase would be an immobile component of the factory, and DNA loops would appear and disappear as polymerases initiate, elongate, and terminate transcription. Each factory contains only one type of RNA polymerase, and factories may be enriched in specific transcription factors involved in the transcription of specific groups of genes (Bartlett et al. 2006). The genes near the factory would be more likely to be transcribed. When released after termination, a gene would still be near a factory and still carry the active histone modifications that could keep it in an open state, leading to efficient reinitiation (Bartlett et al. 2006). In agreement with this concept, domains of decondensed and recently transcribed chromatin carry histone marks that are associated with active transcription (Muller et al. 2007).

What is the driving force to move the DNA template toward the transcription sites? One possibility is that active polymerase can function as a motor that pulls in its template. Optical tweezers experiments showed that the force produced by a single polymerase molecule during transcription can be substantially larger than those produced by the cytoskeletal motors kinesin and myosin (Yin et al. 1995). Alternatively, other molecular motors such as nuclear actin and myosin could be involved in the relocalization of the DNA template. Another unresolved issue concerns the anchoring of transcription sites. Many active genes and transcription factors are associated with the "nuclear matrix," an ill-defined and controversial nuclear substructure (Jackson and Cook 1985; Davie 1995; Iborra et al. 1996; Kumar et al. 2007).

Although the model of "transcription factories" fits with the observation that active genes can transiently cluster (Simonis et al. 2006), one has to keep in mind that biochemical evidence for these "transcription factories," including their isolation and functional characterization, is still missing. Future experiments are needed to validate this model and to prove the functional relevance of transcription factories.

\section{Organization of chromosomes in interphase nuclei}

Via its association with histones and other nonhistone proteins, the DNA is packed into a higher-order chromatin structure. More than 120 years ago, Rabl suggested that chromatin is not randomly organized, but occupies discrete territories. Almost 100 years later, Cremer et al. (1982) showed that UV irradiation of specific interphase nuclear areas damaged discrete chromosomal regions, suggesting that chromosomes occupy distinct positions in the nucleus, the so-called interphase chromosome territories (for review, see Cremer et al. 2006; Heard and 
Bickmore 2007). By using specific probes for individual chromosomes for in situ hybridization, several groups confirmed that each chromosome occupies a specific territory in the nucleus (Borden and Manuelidis 1988; Cremer et al. 1988; Pinkel et al. 1988). These territories are nonoverlapping, and-at least in mammalian cells-homologous chromosome territories are usually not adjacent (Cremer et al. 2001). The most gene-rich chromosome territories tend to concentrate in the nuclear interior, whereas gene-poor chromosomes tend to localize toward the nuclear periphery (Croft et al. 1999; Boyle et al. 2001). The organization of chromosomes in specific territories has been proposed to facilitate interactions of chromosomes with other chromosomes and, therefore, chromosomal territories may have major implications in DNAdependent processes, such as transcription.

The evidence for a relationship between physical chromosome size and nuclear position is still conflicting (Croft et al. 1999; Cremer et al. 2001). The chromosome territories are dynamic and plastic structures. Individual chromosomal regions can be dynamically repositioned. Upon cell cycle exit, a gene-poor human chromosome can move from the nuclear periphery to a more internal site and after re-entry into the cell cycle, the chromosome moves back to the periphery (Wilmut and Campbell 1998; Bridger et al. 2000).

\section{Localization within the chromosome territories}

Initial studies proposed a model of a distinct boundary at the surface of the chromosome territories, with the territory on one side and the interchromosomal space containing the transcriptional machinery on the other side. Generally, inactive genes tend to be located in interior regions of chromosome territories, whereas active genes tend to concentrate along the periphery close to the interchromosomal space (Cremer et al. 2001). However, this general rule seems to be an oversimplification. In contradiction to this rule, studies of the $11 \mathrm{p} 13$ locus, containing ubiquitously expressed genes and tissue-specifically expressed genes, showed that this locus is located within a discrete chromosome territory, and that after activation of tissue-specific genes, these genes were not relocated to the periphery of the territory (Mahy et al. 2002a,b).

The question arises as to how the borders of territories are defined and as to whether different chromosome territories are completely separated or whether chromosomes can intermingle. Volpi et al. (2000) showed that the gene-rich major histocompatibilty complex (MHC) can be found on large chromatin loops, containing several megabases of DNA that extend outward from the chromosome territory (see Fig. 1B). Interestingly, transcriptional up-regulation of the $M H C$ genes led to an increase in the frequency with which this cluster was found on a chromatin loop extending out of the chromosome territory (Volpi et al. 2000). The HoxB gene cluster is another interesting example for looping out of the chromosome territory. Activation of the HoxB gene cluster during differentiation correlates with its relocaliza-
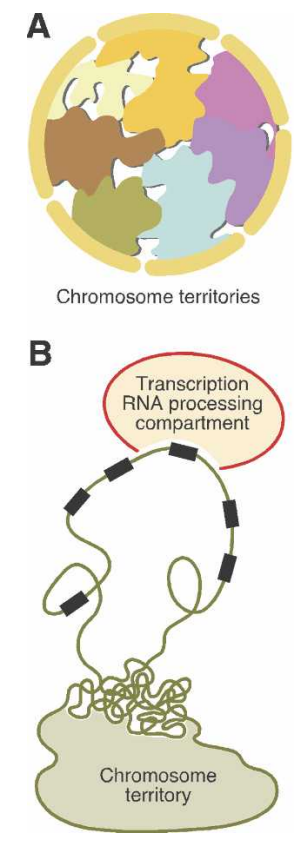

Figure 1. Chromosome territories and looping out of multigene clusters. (A) Schematic structure of chromosome territories and interchromatin space. Chromosomes occupy discrete territories in the nucleus, whereby "decondensed" chromatin loops form the borders of territories, but also intermingle with neighboring chromosome territories. $(B)$ Schematic structure of a transcriptionally active multigene cluster that loops out of the chromosome territory.

tion away from its chromosome territory /Chambeyron and Bickmore 2004). Thus, the surface of the chromosome territories can be increased by looping out of DNA into the interchromosomal compartment and by infoldings of the interchromosomal compartment into the territories (Cremer et al. 2006; Heard and Bickmore 2007. This revised model of chromosomal territories also takes into account that active genes in the interior of chromosome territories (such as active genes in the $11 \mathrm{p} 13$ locus) are accessible for the transcription machinery through DNA-free channels (Cremer et al. 2006). In several studied examples, such as the $\operatorname{Hox} B$ gene cluster, looping out of the chromosome territories correlates with "decondensation" of the chromatin, which is required for transcription and for the flexibility of the looped-out chromatin fiber (Chambeyron and Bickmore 2004). However, this looping and the chromatin "decondensation" are not always linked. For example, in the Hoxd locus, decondensed alleles can be found within the chromosome territories and, conversely, looped-out gene loci can still be condensed (Morey et al. 2007). These findings suggest that looping out and decondensation are not causally coupled and could constitute two separate modes of regulation. Therefore, it will be interesting to investigate how histone modifications (see below) are involved in the looping out and decondensation of specific gene loci such as $\operatorname{Hox} B$ and $\operatorname{Hox} D$.

Recent studies applying high resolution in situ hybridization and chromosome conformation-capture assays 
revealed that chromatin fibers from the periphery of chromosome territories are intermingled in interphase nuclei (Branco and Pombo 2006; Simonis et al. 2006). Interestingly, blocking transcription can change the patterns of intermingling of territories without changing the general properties of the chromosome territories (Branco and Pombo 2006). The looped-out, activated Hox $B$ gene locus shows increased interchromosomal interactions, as compared with the inactive locus, which interacts preferentially with other loci on the same chromosome (Wurtele and Chartrand 2006). The current view is that the chromosome territories have a spongelike architecture with the interchromatin compartment meandering into the territories through the infoldings, whereby some gene loci loop out of the territories, resulting in intermingling of different territories /Cremer et al. 2006). Thus, intrachromosomal interactions would favor compactness of the chromosome territories, whereas interchromosomal interactions would favor intermingling. The balance between these two interactions appears to depend on transcription, chromosome structure, and chromatin modifications.

\section{Chromatin modifications}

Inactive and active chromatin domains can also be defined molecularly by the presence of specific post-translational histone modifications. To date, numerous histone modifications have been described (for review, see Kouzarides 2007). Histones can be methylated at arginines or lysines, phosphorylated on serines and lysines, acetylated on lysines, sumolyated and ubiquitinated on lysines, and ADP-ribosylated. Moreover, the number of methyl groups added to a single lysine or arginine residue can vary. Lysine residues can be mono-, di-, or trimethylated, and arginine residues can be monomethylated and symmetrically or asymmetrically dimethylated. Importantly, the precise methylation status (mono-, di-, or trimethylation) can influence the transcriptional status of genes (Schneider et al. 2004). These modifications could directly affect the structure of chromatin; e.g., by neutralizing the positive charge of histones. In addition, the enormous combinatorial potential of these modifications can be read out by proteins that bind to specific modifications, which has provided the basis for the socalled histone "code" hypothesis (Turner 1993; Strahl and Allis 2000). Although it is still unproven whether these modifications form a true "code," it is now well established that they are involved in the regulation of gene expression (Turner 2007).

In the last few years, many of the enzymes that add these modifications, such as histone acetyltransferases, lysine and arginine methyltransferases, and enzymes that can remove these modifications, such as histone deacetylases, was described (for review, see Couture and Trievel 2006). In contrast to histone acetylation, the lysine methylation had been considered to be a very stable modification, but the recent discovery of lysine demethylases (Shi et al. 2004) revealed that lysine methylation can also be dynamic. Interestingly, many of the genes encoding enzymes modifying histones have been found to be rearranged, amplified, or mutated in various types of cancer (Schneider et al. 2002). Several studies focusing on specific genes or loci showed that active chromatin is generally enriched in acetylated histones H3, H4, H2A (Davie and Candido 1978), and histone H3 that is methylated at Lys 4 (H3/K4) (Litt et al. 2001). H3/K4 di- and trimethylation and $\mathrm{H} 3$ acetylation correlate globally with open chromatin (The ENCODE Project Consortium 2007). In contrast to this, inactive chromatin is characterized by histone hypoacetylation and methylation of histone H3 Lys 9 (H3/K9) (Litt et al. 2001). The methylation of $\mathrm{H} 3 / \mathrm{K} 9$ has been thought to be a mark for heterochromatin. Methylated H3/K9 can be "read out" by the Heterochromatin Protein 1 (HP1), a structural component of condensed chromatin that specifically recognizes and binds to the methylated form of H3/K9 (Bannister et al. 2001; Lachner et al. 2001). The loss of K9 methylation in heterochromatin can affect the heterochromatin organization (Peters et al. 2001). Interestingly, HP1 itself interacts with the enzyme that methylates $\mathrm{H} 3 / \mathrm{K} 9$, forming a positive feedback loop that would allow heterochromatin to spread over large chromosomal regions until further spreading is prevented by a boundary element (Bannister et al. 2001; Lachner et al. 2001).

Changes in chromatin structure that include modifications of histones may also have a role in the positioning of chromosomes. Long-term treatment of cells with trichostatin A, an inhibitor of histone deacetylases that increases the acetylation level of histones, results in large-scale movement of centromeric and pericentromeric chromatin to the nuclear periphery. After drug removal, these changes in localization are rapidly reversed (Taddei et al. 2001).

Recent genome-wide mapping studies of histone modifications that combined chromatin immunoprecipitation (ChIP) with microarrays or direct sequencing allowed for high-resolution mapping of many histone marks (Barski et al. 2007). So far, these studies have revealed that actively transcribed chromatin regions are enriched in H3/K4 mono-, di-, or trimethylation, H3/K36 trimethylation, and monomethylation of $\mathrm{H} 3 / \mathrm{K} 9, \mathrm{H} 3 /$ $\mathrm{K} 27$, and H4/K20. The distribution of these marks over the transcribed region of genes is not equal; trimethylation of $\mathrm{H} 3 / \mathrm{K} 4$ is enriched at the $5^{\prime}$ end of transcribed regions and can serve as an indicator for transcription start sites, whereas H3/K36 methylation is enriched at the 3 ' end and may be linked to processing of the transcripts (Bannister et al. 2005). In contrast to this, trimethylation of $\mathrm{H} 3 / \mathrm{K} 9, \mathrm{H} 3 / \mathrm{K} 27$, and $\mathrm{H} 3 / \mathrm{K} 79$ is linked with repression (Barski et al. 2007). Interestingly, active promoters and enhancers are found to be associated with $\mathrm{H} 3 / \mathrm{K} 4$ methylation and H3/K9 monomethylation. Additionally, active promoters can be identified by the presence of further activating marks that are linked with transcriptional elongation (such as H3/K36 methylation) downstream in the transcribed region of the gene (see Fig. 2; Barski et al. 2007). These criteria can be used to identify active promoters. Interestingly, at genes that are not regulated at the level of transcription initiation 


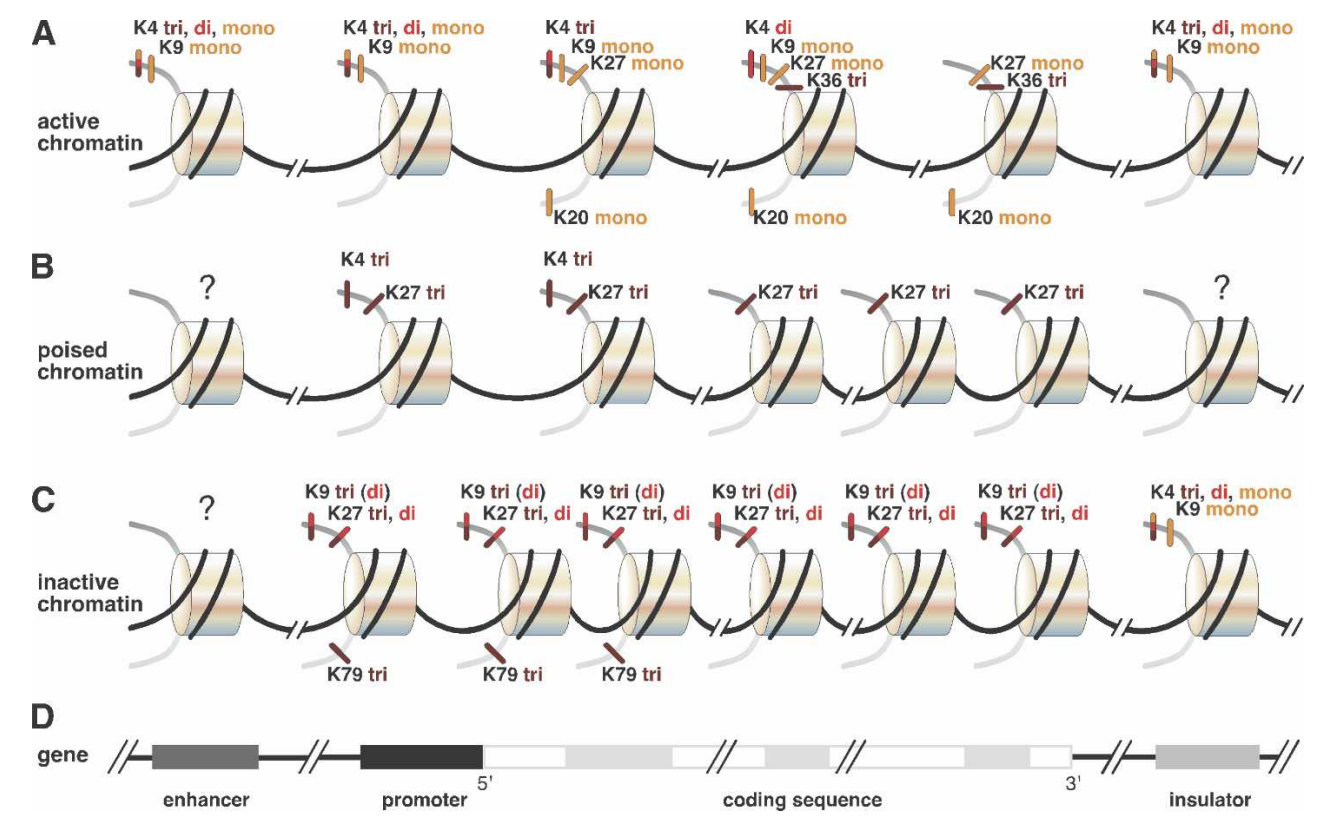

Figure 2. Schematic overview of histone modifications. (A) Active chromatin marks. Nucleosomes encompassing the transcribed region of a gene-a promoter, enhancer, and insulator, respectively-are shown (structure of gene and regulatory elements are represented below). The N-terminal "tails" of histone H3 are shown in dark gray, and the tails of H4 are in light gray. H3/K4 methylation and H3/K9 monomethylation are enriched at the enhancer, the promoter, and the 5' end of the active gene. H3/K27 and H4/K20 monomethylation is enriched over the transcribed region, whereas H3/K36 trimethylation peaks at the $5^{\prime}$ of the active gene. Note that active genes are also enriched in $\mathrm{H} 3, \mathrm{H} 4$, and H2A acetylation (not shown). (B) Poised chromatin marks. Four nucleosomes encompassing the transcribed region of a gene poised for transcription and one nucleosome each on a promoter element, an enhancer element, and an insulator are shown. The promoter and the transcribed region are enriched in the repressive mark H3/K27 trimethylation, whereas the region around the transcription start is also enriched in the active mark H3/K4 trimethylation. This combination of active and repressive marks can poise genes for activation and forms a so-called "bivalent domain." $(C)$ Inactive chromatin marks. Modifications of histones H3 and H4 in nucleosomes encompassing a repressed or silenced gene are shown. The coding sequence and promoter of the inactive gene are enriched in $\mathrm{H} 3 / \mathrm{K} 9$ and $\mathrm{H} 3 / \mathrm{K} 27$ di- and trimethylation. The $5^{\prime}$ end of the gene and the promoter region are marked by H3/K 79 trimethylation, whereas the insulator element carries activating marks. Data are based on Barski et al. (2007). (D) Scheme of a protein-coding gene with exons shown as light-gray boxes and introns as white boxes. Cis-acting regulatory sequences (enhancer, promoter, and insulator) are represented by black and dark-gray boxes.

(polymerase II can be found at these genes) but rather elongation, H3/K4 methylation is enriched at the promoter. Consistent with the post-initiation regulation of these genes, marks linked with transcriptional elongation are absent (Guenther et al. 2007). However, this "black-and-white" picture of active and repressive marks may be an oversimplification. Some activating marks are not only found on genes that are transcribed, but also on genes that are poised for transcription. A nice example is provided by genes that are stimulated by endotoxins in macrophages. A subset of these genes maintains some activating marks after initial induction, priming them for efficient reactivation (Foster et al. 2007). Additionally, modifications considered to be repressing, such as $\mathrm{H} 3 / \mathrm{K} 9$ dimethylation, can be found not only in heterochromatin but also on certain active genes. Furthermore, in so-called "bivalent chromatin domains" repressive marks (H3/K27 trimethylation) and activating marks (H3/K4 trimethylation) can coexist (see below; Azuara et al. 2006; Bernstein et al. 2006; Lee et al. 2006). These findings suggest that the histone "code" is more complex than initially expected and that not single modifications, but rather the combination of modifications is an indicator for the transcriptional state.

In the rapidly developing field of chromatin modifications, many exciting questions are waiting to be addressed. Currently, little is known about how these modifications can regulate the localization of specific genes. Are histone modifications involved in tethering the genes to a particular nuclear region or compartment? Are histone modifications the cause or the consequence of active/inactive chromatin domains? What is their role in establishing or maintaining nuclear domains? How do they change when genes loop out of their chromatin territory? It will be exciting to understand precisely how histone modifications regulate the functional status not only of specific genes but also of chromatin domains and to link the modification status with specific gene localizations or relocalizations of genomic regions.

\section{Mobility and movements of gene loci}

The mobility and movements of gene loci have been studied extensively by live cell imaging of transgenic 
arrays of fluorescently labeled lac operators that have been stably integrated in various chromosomal locations. These studies indicated that the mobility of such transgenes is predominantly confined to the radius of chromosomal territories and depends on their relative nuclear localization (Vazquez et al. 2001). Moreover, transgenes that are localized near the nuclear periphery or are associated with the nucleolus were found to be less mobile than transgenes residing in the nucleoplasm (Chubb et al. 2002). Finally, chromatin repositioning was detected predominantly in the G1 phase of the cell cycle (Thomson et al. 2004). Although the molecular basis for chromatin repositioning is fairly obscure, the spatial distribution in the nucleus has been implicated in the establishment and maintenance of active, poised, or repressed chromatin states.

\section{Association of genes with the nuclear periphery and nuclear pores}

Early electron microscopic analysis of calf thymus nuclei revealed a peripheral localization of condensed heterochromatic regions (Mirsky and Allfrey 1960). In yeast, a role of the nuclear periphery in gene silencing was shown by the artificial tethering of a reporter gene to the nuclear envelope via a membrane-spanning anchor (Andrulis et al. 1998). In these experiments, the reporter gene had been linked to silencer sites that mediate the binding of silent information regulators (Sir proteins). Immunolocalization studies indicated that Sir proteins accumulate near the nuclear periphery in telomere foci, thus apparently contributing to the silencing of genes localized near the nuclear periphery (Maillet et al. 1996). However, silencing can persist in the absence of anchorage to the nuclear envelope (Gartenberg et al. 2004). The molecular basis for anchoring the Sir protein complex to the nuclear periphery has been elucidated by demonstrating that Sir4 interacts with the membrane-associated protein Esc1, which is localized at the nuclear periphery, but does not colocalize with nuclear pores (Andrulis et al. 2002).

In addition to the role of the nuclear periphery in gene silencing (see Fig. 3), nuclear pores have been implicated in the protection of accessible chromatin regions from spreading repression by heterochromatin. A genetic screen in yeast aimed at identifying components that confer chromatin boundary activity upon a synthetic boundary element led to the identification of several genes that had been implicated previously in nuclearcytoplasmic trafficking of tRNA and mRNA (Ishii et al. 2002). Proteins involved in trafficking of tRNA and mRNA are known to interact during transit with receptors of the inner basket of the nuclear pore complex. In particular, the Nup2p component of the nuclear pore complex has been shown to mediate the boundary activity by the physical tethering of boundary elements to the nuclear pore basket (Ishii et al. 2002). The potential interaction of transcribed genes with the nuclear pore complex has also been studied by time-lapse studies of live cells and by chromatin endogenous cleavage (ChEC) experiments. In genome-wide ChEC experiments, in which the Nup2p protein has been fused to micrococcal nuclease to cleave DNA that interacts with the nuclear pore, numerous transcribed genes were found to interact with

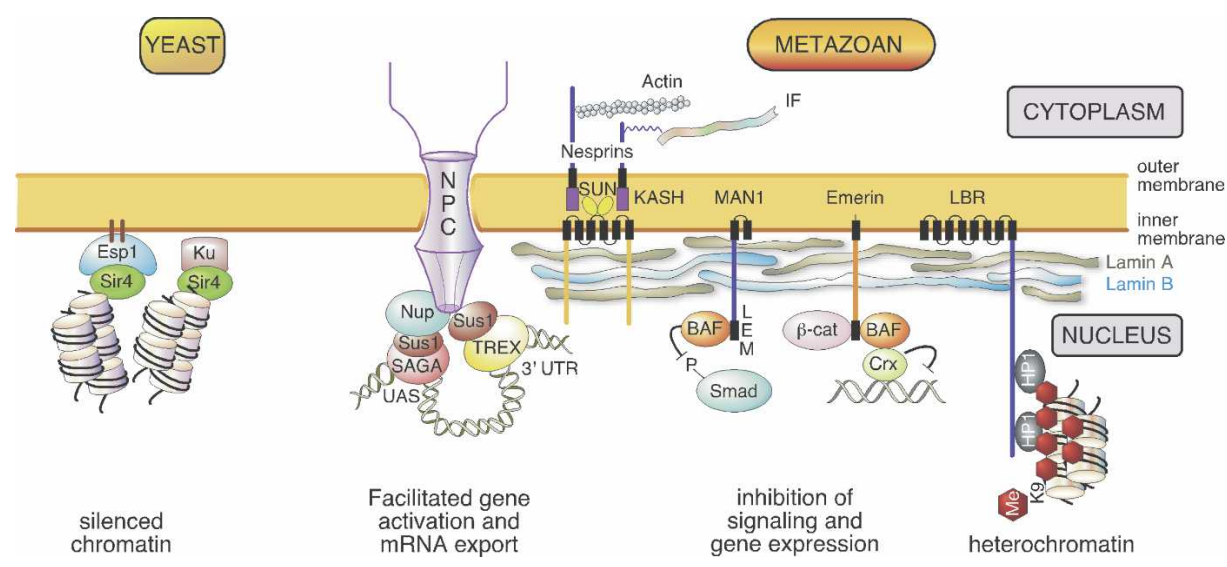

Figure 3. Structural and functional hallmarks of the nuclear periphery in yeast and metazoans. The membrane bilayer of the nucleus is perforated by nuclear pores, which consist of an $\sim 30$-subunit-containing nuclear pore complex (NPC). (Left) In yeast, the Nup1 and Nup2 components of the nuclear pore complex have been found to interact with components of the SAGA coactivator complex via Sus1, which is also a component of the TREX complex, involved in mRNA export. The nuclear periphery, excluding the pores, is also implicated in gene silencing, whereby the yeast Sir4 protein is tethered to the periphery via the enhancer of silent chromatin (Esc1) or Ku protein. (Right) In metazoans, the inner nuclear membrane is associated with lamins and lamin-associated proteins. The lamin $\mathrm{B}$ receptor (LBR) has been implicated in heterochromatin regulation via interaction with HP1, which binds to histone H3K9 trimethyl marks. Emerin and Man1 recruit, via their LEM domain, the barrier to autointegration factor (BAF), which associates with transcription repressors such as Crxl. In addition they bind and inhibit the function of the signaling effectors Smad and $\beta$-catenin. The SUN-Nesprin complex, which is formed by an interaction of the KASH domain of Nesprin with SUN proteins, links the perinuclear skeleton with the cytoplasmic filament system. (IF) Intermediate filament. 
the nuclear pore complex via promoter sequences (Marshall et al. 1997). Likewise, genome-wide analysis of DNA that had been coimmunoprecipitated with components of the nuclear pore complex indicated that transcriptionally active genes are enriched in the immunoprecipitated fractions (Casolari et al. 2004). Together, these studies provided experimental support for the "gene gating hypothesis," in which transcribed genes were postulated to be moved into the vicinity of the nuclear pore to facilitate mRNA export (Blobel 1985).

Recently, several studies have examined the relationship of transcriptional activation of genes and the positioning of active genes at the nuclear pore complex (see Fig. 3). Although all studies could demonstrate that genes become stably associated with the nuclear pore complex upon induction, the promoter-bound components that are involved in peripheral gene localization appear to differ for individual genes (for review, see Akhtar and Gasser 2007). In particular, the association of GAL genes with the nuclear pore complex was shown to involve the transcriptional coactivator complex SAGA, which serves as an adaptor for the mediator complex (Cabal et al. 2006). Deletion of either the SAGA component Ada2 or the nuclear pore component Nup1 impaired the perinuclear gene confinement, but did not affect gene transcription. Interestingly, the SAGA-associated protein Sus1 also copurifies with components of the mRNA export machinery that bind Nup1 (RodriguezNavarro et al. 2004). Thus, Sus 1 may provide a physical link between promoter-bound activators and the mRNA export machinery. Analysis of dynamic 3D tracking of the yeast GAL gene locus also indicated that transcriptional activation not only results in a confinement at the nuclear periphery, but also in constraining the dynamic mobility (Cabal et al. 2006). In contrast, a study by Laemmli and colleagues (Schmid et al. 2006) indicated that the interaction of the GAL genes with Nup2 requires the UAS-bound Gal4 activator protein and the TATA box, but not the SAGA complex or active transcription. As the ChEC experiments also score transient and weak interactions, the contribution of the SAGA complex to positioning of transcribed genes at the nuclear periphery may have been underestimated.

In higher eukaryotes, the nuclear envelope contains the nuclear lamina, which represents a layer of intermediate filament proteins between chromatin and the inner nuclear membrane. Two proteins, Emerin and Man1, have been shown to play an important role in the tethering of repressed genes to the nuclear periphery (Liu et al. 2003). Both proteins have a LEM domain that recruits autointegration factor (BAF), which associates with transcription repressors, such as Crxl (for review, see Schirmer and Foisner 2007). In addition, Man1 can interact with Smads and $\beta$-catenin, antagonizing signaling by TGF $\beta$ and Wnt proteins, respectively (Pan et al. 2005; Markiewicz et al. 2006). Moreover, the lamin B receptor (LBR) has been implicated in heterochromatin regulation via interaction with $\mathrm{HP} 1$, which binds to histone H3K9-trimethyl marks (Makatsori et al. 2001; Polioudaki et al. 2001). Finally, the SUN-Nesprin com- plex links the perinuclear skeleton with the cytoplasmic filament system (for detailed review, see Schirmer and Foisner 2007).

Recently, a genome-wide analysis of DNA sequences that are positioned at the nuclear periphery was performed by expressing a lamin-DNA adenine methyltransferase fusion in Drosophila cells. This study identified several hundred genes as lamin-associated genes and revealed that these genes lack active histone modifications and are late replicating (Pickersgill et al. 2006).

\section{Changes in subnuclear gene localization during cell differentiation}

3D-FISH of individual genes in fixed cells indicated that their position relative to other genes or subnuclear compartments can change at different stages of gene activation and/or cell differentiation. In particular, the localization of the immunoglobulin heavy-chain gene cluster has been shown to change from a peripheral position in nonlymphoid cells to the nuclear interior in pre-B cells (Brown et al. 2001; Kosak et al. 2002). Likewise, largescale chromatin reorganization and nuclear repositioning from the periphery to the center have been described for the association of the Mash1 locus during neural induction (Williams et al. 2006). Although a 2-Mb genomic segment was found to relocalize, the changes of subnuclear position did not correlate with gene activity, as some but not all genes within the $2-\mathrm{Mb}$ segment are transcribed upon neural induction. The lack of a simple correlation between gene activation and the localization from the nuclear periphery to the center was further inferred from the analysis of the interferon- $\gamma$ locus, which remains localized at the nuclear periphery upon gene activation, and the murine $\beta$-globin locus, which is repositioned to the center subsequent to gene activation (Hewitt et al. 2004; Ragoczy et al. 2006).

Another type of intranuclear chromatin movement has been observed in antigen receptor gene loci that undergo somatic recombination in lymphocytes. The immunoglobulin heavy- and light-chain gene clusters and the T-cell receptor- $\alpha$ and $-\beta$ gene loci contain discontinuous variable $(\mathrm{V})$, diversity $(\mathrm{D})$, and joining $(\mathrm{J})$ gene segments that are spread over regions of $0.7-3 \mathrm{Mb}$ and are assembled by RAG-mediated gene rearrangement (for review, see Bassing et al. 2002). In these gene clusters, hundreds of variable gene segments that are spread out over chromosomal regions of up to $2.5 \mathrm{Mb}$ become juxtaposed with diversity or joining segments that are far apart from distal V segments. 3D-FISH analysis of the antigen receptor loci revealed large-scale chromatin movements that can be accounted for by looping-mediated chromosome "contraction" (Kosak et al. 2002; Fuxa et al. 2004; Sayegh et al. 2005; Skok et al. 2007). The looping of individual subdomains of the large gene loci may facilitate or reflect synapse formation between distal V segments and proximal D or J segments. Notably, the chromosomal contractions are transient and are followed by both a chromosomal "decontraction" that separates V and J segments and the recruitment of the 
locus to pericentromeric heterochromatin (Roldan et al. 2005; Skok et al. 2007). For the immunoglobulin heavychain locus, the decontraction has been shown to occur at a developmental stage in which the productive gene rearrangement of one allele produces an active pre-B-cell receptor that generates a negative feedback signal, resulting in decontraction of the other allele and "allelic exclusion" (Roldan et al. 2005). Similar transient chromosomal contractions have been described for the T-cell receptor $\beta$ and $\alpha$ loci (Skok et al. 2007). The decontraction that separates $\mathrm{V}$ and $\mathrm{J}$ segments appears to represent a general principle underlying allelic exclusion, which is established as an allelic asynchrony in early stages of mouse embryogenesis (Mostoslavsky et al. 2001; Goldmit et al. 2005). Although the molecular basis for the establishment of allelic asynchrony is still unclear, differential demethylation and replication timing of the two alleles may represent an important mechanism (Mostoslavsky et al. 2001).

The molecular mechanisms underlying the changes of gene localization from perinuclear or heterochromatic regions to transcription factories or euchromatic regions are still obscure, but seem to correlate with histone acetylation (Chowdhury and Sen 2001; Hawwari and Krangel 2005) In contrast, some insight into the molecular basis for the intrachromosomal "contraction" of the immunoglobulin heavy-chain cluster has been provided by the analysis of knockout mice. Both Pax5-deficient mice and mice defective in the Ezh2 component of the PRC2 polycomb repressive complex (an H3/K27-specific histone methyltransferase) have been shown to fail to undergo intrachromosomal contractions (Fuxa et al. 2004). This was found to be dependent on the function of the transcription factor Pax5 and on the Ezh2 component of the Polycomb repressive complex PRC2 (Su et al. 2003). The recruitment of PRC2 and the accompanying methylation of Lys 27 of histone $\mathrm{H} 3$ at the immunoglobulin heavy-chain locus may attract the PRC1 complex and result in contraction of the locus (Francis et al. 2004; Su et al. 2005), suggesting a role of this histone mark in the locus contraction.

\section{Interchromosomal interactions}

The positioning of multiple genome regions on different chromosomes relative to each other is a rapidly emerging new and important determinant for their function. The local clustering of genes can have regulatory function; e.g., by regulating their expression or allowing interactions with key regulatory elements (for review, see Misteli 2007). Here we will discuss examples for homolog and nonhomolog interchromosomal interactions often also termed "chromosome-kissing."

\section{Homologous interchromosomal interactions}

Physical pairing of chromosomes is particularly visible in dipteran insects such as Drosophila. Such pairing may enable one allele to support the function of the second allele (for reviews, see Pirrotta 1999; Duncan 2002). E.B.
Lewis termed this process "transvection." He found that the phenotypes of mutant Ubx (Ultrabithorax) alleles were stronger when pairing with a wild allele was prevented by chromosomal rearrangements. The pairing can increase $U b x$ expression and allows the alleles to partially complement each other. This transvection, whereby a mutation can be complemented in trans by the other allele, has now been shown for a number of loci in Drosophila (Duncan 2002). Another well-studied example is the Hox gene $A b d-B$ (Abdominal-B). Genetic studies have demonstrated that transvection of $A b d-B$ depends on a 3 '-flanking region termed the TMR (transvection-mediating region) (Hopmann et al. 1995). Using RNA FISH, M. Levine's group (Ronshaugen and Levine 2004) was able to visualize transvection events. They showed that $A b d-B$ enhancers located on one chromosome can frequently pair with the $A b d-B$ gene located on the other homolog chromosome. The TMR sequence functions as a pairing element. Interestingly, this TMR contains a Polycomb-responsive element (Zhou and Levine 1999; Zhou et al. 1999; Bantignies et al. 2003). The colocalization allows the enhancers that normally loop in cis to target promoters at the same chromosome to loop in trans and activate the $A b d-B$ gene in trans. The tighter the pairing is, the more frequent are the trans-interactions between the enhancer and the $A b d-B$ gene (Ronshaugen and Levine 2004).

Another well-studied example for interchromosomal interactions of homolog chromsomes is the mammalian X chromosome (for a review, see Carrel 2006). X-chromosome inactivation involves the counting of the chromosomes and subsequent choosing of which of the two $\mathrm{X}$ chromosomes becomes inactivated. This requires "communication" between the two X chromosomes that could occur through homolog chromosome interactions (Marahrens 1999). In the last few years significant insight into the pairing of the two $\mathrm{X}$ chromosomes was obtained. Critical for X inactivation is the Xic (X inactivation center) region (Brown et al. 1991; Lee 2005). In two elegant studies, the groups of Lee and Heard (Bacher et al. 2006; Xu et al. 2006) used FISH in mouse female embryonic stem (ES) cells to demonstrate that during the onset of $\mathrm{X}$ inactivation, the $\mathrm{X}$ chromosomes move from the nuclear periphery, where they have random positions relative to each other, and come into close proximity with their Xic regions juxtaposed. The two X chromosomes are only found together at the time during early ES cell differentiation when $\mathrm{X}$ inactivation is triggered, but not at later or earlier time points (Fig. 4). Interestingly, deletion mutants in the Xic region that disrupted random $\mathrm{X}$ inactivation also strongly affected the pairing between the X chromosomes (Bacher et al. 2006; Xu et al. 2006). During the pairing, the two $X$ chromosomes are physically interacting, directly or via their DNA-bound proteins (Xu et al. 2006), allowing cross-talk and mutually exclusive designation of the active or inactive state. After dissociation of the two homologous partners, the inactive $\mathrm{X}(\mathrm{Xi})$ is targeted to the perinucleolar compartment (Fig. 4; Zhang et al. 2007). The $\mathrm{Xi}$ is organized as a repeat-rich core with the gene-rich regions around 


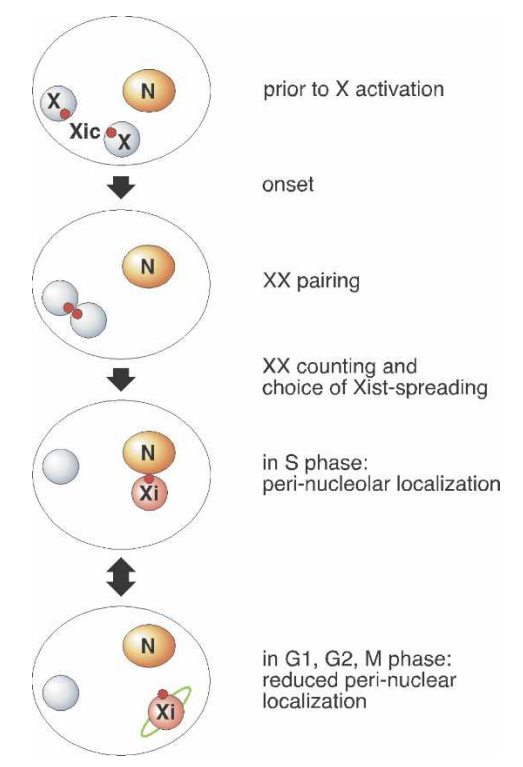

Figure 4. Nuclear reorganization during $X$-chromosome inactivation. After female ES cells start to differentiate, both X chromosomes (shown as chromosome territories in blue) come close together via juxtaposition of the $\mathrm{X}$-inactivation centers (Xic; red dots). This "kissing" of the $\mathrm{X}$ chromosomes is accompanied by the process of X-chromosome counting and the choice of the $\mathrm{X}$ chromosome that will be inactivated. On the future Xi chromosome, the Xist RNA (red) is up-regulated and spreads, excluding the transcription machinery. Upon dissociation of the paired $\mathrm{X}$ chromosomes, the $\mathrm{Xi}$ is targeted to the perinucleolar compartment (nucleus in brown), where the condensed chromatin can be replicated. During S phase the Xi has to visit the perinucleolar compartment for replication. In the other phases of the cell cycle, the Xi can be found in other locations (e.g., nuclear periphery). Genes on the $\mathrm{Xi}$ that escape $\mathrm{X}$ inactivation are located outside of the Xist-covered Xi-chromosome territory.

(Chaumeil et al. 2006; Clemson et al. 2006). According to the current model, the repeat-rich/gene-poor regions within the Xi-chromosome territory become inactivated first, triggered by the accumulation of Xist RNA forming a Xist-mediated barrier. RNA polymerase II and transcription factors are excluded from this core region. Silenced genes are moved toward this repeat-rich core, whereas genes that escape X inactivation and are transcribed are located outside or at the periphery of the Xichromosome territory (Chaumeil et al. 2006). Processes involved in the inactivation include incorporation of the histone variant macro H2A (Mermoud et al. 1999) and an enrichment of inactive chromatin marks such as DNA methylation (Norris et al. 1991), dimethylation of H3/K9 (Heard et al. 2001; Mermoud et al. 2002), and trimethylation of H3/K27 (Plath et al. 2003; Silva et al. 2003), as well as a depletion of active marks such as acetylation of H3 and H4 (Jeppesen and Turner 1993; Boggs et al. 1996) and methylation of $\mathrm{H} 3 / \mathrm{K} 4$ (Boggs et al. 2002).

The $\mathrm{Xi}$ associates during $\mathrm{S}$ phase with the perinucleolar compartment, which is specialized in replicating condensed chromatin to propagate its repressive character, but it can locate to the nuclear periphery in the other phases of the cell cycle. This perinucleolar localization correlates with late replication timing of the $\mathrm{Xi}$, which is typical for repressed and condensed chromatin (Schwaiger and Schubeler 2006). Autosomes with ectopic insertions of the Xic region are also targeted to the perinucleolar compartment, suggesting a role of Xic for this relocalization (Zhang et al. 2007).

Targeted chromosome movements and the interchromosomal pairing of the two $\mathrm{X}$ chromosomes are important for X chromosome inactivation. They are also an example for two chromosomes that have two opposite epigenetic states (active and inactive) and their relocalization to specific subnuclear compartments. At least for the $\mathrm{Xi}$, the localization can also be cell cycle-regulated; i.e., for replication it has to move to the perinucleolar compartment. The Xic region has an important role in these processes, but it is still unclear whether the Xic regions loop out of the chromosome territory to interact with each other and whether other regions of X chromosome are pairing. Moreover, neither the driving force nor the molecular mechanisms of chromosomal relocalization are understood.

\section{Nonhomologous interchromosomal interactions}

The first example for the clustering of nonhomologous genes has been provided by the ribosomal genes that coalesce in the nucleolus. In the nucleolus, the ribosomal gene arrays from several different chromosomes come together (for review, see Raska et al. 2006). In the past few years, new technologies such as high-resolution in situ hybridization and $3 \mathrm{C}$ assays provided additional examples for the clustering of RNA polymerase II-transcribed genes that reside on nonhomologous chromosomes. The human $\alpha$-globin and $\beta$-globin genes on chromosomes 16 and 11 , respectively, are frequently located very close together when they are transcribed during erythroid differentiation (Brown et al. 2006). However, the globin genes do not directly colocalize, and the close spatial proximity is not essential for transcription (Brown et al. 2006).

Recently, the Flavell group (Spilianakis et al. 2005) described the first example where genes on different chromosomes are associating physically to coordinate their expression. In naive $\mathrm{T}$ cells the Ifng (Interleukin) and the Th2 locus are localized together in a region in the nucleus poised for gene expression. Upon stimulation of the naïve $\mathrm{T}$ cells, depending on the stimulus, the Ifng (if the naïve T cells differentiate into TH1 cells) or the Th2 locus (if they differentiate into TH2 cells) becomes activated, whereas the other gene remains inactive. The activated gene keeps its nuclear position, where it is poised for activation, whereas the silent one is moved, presumably to a more repressive region of the nucleus. This moving away replaces the interchromosomal interactions by intrachromosomal interactions (Spilianakis et al. 2005). Unfortunately, the other regions of the genome that are interacting with these loci during T-cell activation are currently not known. Interestingly, in TH1 cells the SATB1 (special AT-rich sequence-binding protein 1) 
protein becomes rapidly induced. SATB1 can organize cell-type-specific nuclear architecture by anchoring DNA and by recruiting chromatin-remodeling factors. In the case of Ifng, SATB1 folds this locus into small interchromosomal loops, which are anchored by SATB1 at their base (Fig. 5). In this $200 \mathrm{~kb}$ of looped chromatin, histones are hyperacetylated and chromatin remodeling factors such as Brg1, specific regulators of Ifng expression, and RNA polymerase II are recruited in a SATB1dependent manner (Cai et al. 2006). These exciting findings using $\mathrm{T}$-cell differentiation as a model show that chromosomal loci leave their chromosome territory for intrachromosomal interactions to occur, and upon differential gene expression they separate again. It also defines a clear role of the SATB1 protein in folding of the Ifng locus into interchromosomal loops. This raises the question of whether this interplay between inter- and intrachromosomal interactions is a general phenomenon occurring in many different cell types or is limited to special events.

Another example for interchromosomal interactions is provided by the odorant receptor genes. In sensory neurons, a single odorant receptor from a large gene family of receptors located on different chromosomes is expressed. Interestingly, the expressed receptor gene has been found by $3 \mathrm{D}-\mathrm{FISH}$ and $3 \mathrm{C}$ analysis to interact with an enhancer element, termed the $\mathrm{H}$ enhancer, on chromosome 14 (Lomvardas et al. 2006). As odorant receptor genes on different chromosomes were found to interact with the $\mathrm{H}$ enhancer, this finding has been interpreted to suggest that the expression of an odorant receptor gene depends
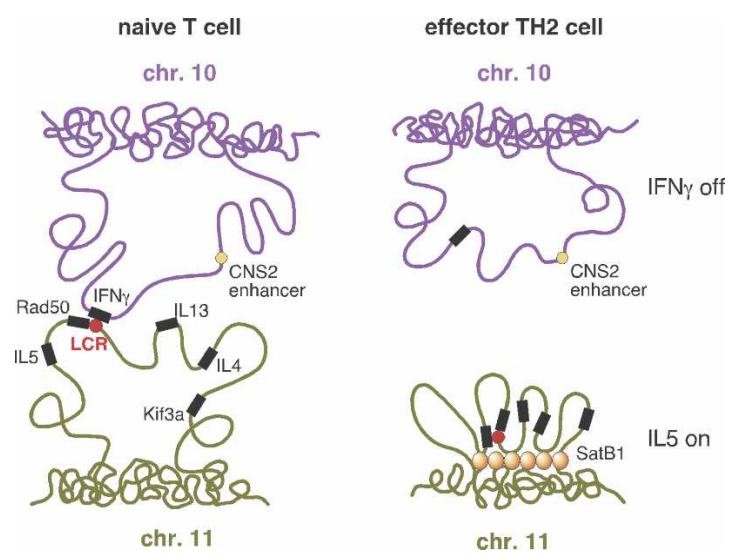

Figure 5. Inter- and intrachromosomal chromatin loops. (Left) In naïve $T$ cells the interleukin gene cluster on chromosome 11-carrying the interleukins IL4, IL5, and IL13-loops out and the locus control region (LCR) residing at the $3^{\prime}$ end of the Rad50 gene interacts with regulatory sequences of the interferon- $\gamma($ IFN $\gamma)$ gene on chromosome 10. This interchromosomal interaction represents a poised chromatin state, as both IL4 and INF $\gamma$ genes are transcriptionally inactive. (Right) In differentiated and IL4-expressing T-helper2 $\left(\mathrm{T}_{\mathrm{H}} 2\right)$ cells, SATB1-mediated chromatin loops facilitate intrachromosomal interactions between IL4 regulatory sequences and the Rad50 locus control region. In $\mathrm{T}_{\mathrm{H}} 2$ cells, the IFN $\gamma$ gene is not transcribed, whereas in $\mathrm{T}_{\mathrm{H}} 1$ cells the IFN $\gamma$ promoter interacts with the CNS2 enhancer by an intrachromosomal loop (not shown). on its association with the enhancer element in trans. Moreover, one allele of the $\mathrm{H}$ enhancer has been shown to be methylated at $\mathrm{CpA}$ residues, providing an appealing model for the one receptor-one cell rule for odorant receptor gene expression. However, the recent analysis of a targeted deletion of the $\mathrm{H}$ enhancer indicated that only the expression of odorant receptor genes located in cis was impaired, whereby genes more distant to the enhancer were less affected by the deletion than enhancerproximal genes (Fuss et al. 2007). This result emphasizes the importance of a functional analysis and suggests that some of the observed interchromosomal interactions may be transient and functionally unimportant.

Interchromosomal interactions are not only involved in regulating gene expression, but also in other processes such as genomic imprinting. The maternal imprinting control region (ICR) on murine chromosome 7 controls not only in cis the expression of the neighboring Igf2/ H19 locus (containing imprinted genes), but also interacts with the Wsb1/Nf1 locus on chromosome 11 and controls its expression in trans (Ling et al. 2006). The interaction of the ICR on chromosome 7 with the Wsb1/ Nf1 locus on chromosome 11 depends on the presence of the boundary element-binding protein CTCF (Ling et al. 2006) bound to the maternal allele, and results in regulated expression of the Wsb1/Nf1 locus. Deletion of the ICR on chromosome 7 or CTCF knockdown affects Igf2 imprinting, suggesting the possibility that the interchromosomal interaction may be necessary for correct imprinting (Ling et al. 2006). This finding provides an interesting example for long-range allele-specific interactions between genomic regions on different chromosomes (Simonis et al. 2006) and shows that the CTCF protein is involved in mediating the interaction. In the future it will be very important to identify additional proteins that are able to mediate interchromosomal interactions in order to gain insight into the still poorly understood molecular mechanism of this interaction. Another recent study using differentiating ES cells mapped $>100$ additional interactions for the H19 ICR, suggesting that this ICR can interact with multiple chromosomal regions in cis and trans (Zhao et al. 2006). Whether these reported differences (very specific with the Wsb1/Nf1 locus versus with a high number) in the interactions of the H19 ICR with other genomic regions are due to a different experimental setup or are cell specific is, as yet, unclear.

Some insights into how these long-distance physical interactions between chromosomes can be mediated came from studies on Polycomb response elements (PRE) in Drosophila. The Fab-7 sequence contains a PRE and regulates the expression of genes in the bithorax locus, a locus subject to extensive regulation throughout development. Fab-7 can act in cis, but when Fab-7 transgenes are inserted in the Drosophila genome, these transgenes (even when on different chromosomes) and the endogenous Fab-7 frequently associate in a process also called trans-sensing of homologous sequences. These associations depend on the presence of Polycomb-group proteins (Bantignies et al. 2003). Interestingly, components 
of the RNA interference (RNAi) machinery, such as dicer-2, as well as Argonaute genes are required for the long-distance interactions. The RNAi machinery is not required for establishment of the interchromosomal interactions, but for its maintenance (Grimaud et al. 2006). The following model had been put forward: Once the pairing is established, sense and antisense transcription in the vicinity is stimulated, and the RNAi machinery produces small interfering RNA (siRNA). The siRNA can then be bound by Polycomb-group proteins to act as molecular glue that stabilizes the chromosomal interaction and the silencing of both loci (Grimaud et al. 2006; Lei and Corces 2006). While providing some first clues about a role of RNAi in the physical interaction between different chromosomes, many mechanistic questions of how these interactions are mediated remain open. Intense work and new techniques will be required to investigate the role of RNA in interchromosomal interactions and to fully understand how these interactions are mediated.

Recent findings again raise the question of how general the interchromosomal cross-talk is. A recent study of the mouse Hox gene clusters demonstrated that the coregulation of the four clusters localized on different chromosomes is not associated with colocalization of the loci (Lanctot et al. 2007). These results demonstrate that coregulation of Hox genes can be independent of colocalization. Additionally, the active $\alpha$ - and $\beta$-globin genes colocalize only in human but not in mouse erythroblasts. This difference may be due to different chromosomal context; the mouse locus lies in a gene-poor region near the centromere, whereas the human locus is located in a gene-rich subtelomeric region (Brown et al. 2006). This suggests that not only transcriptional regulation but also additional factors such as chromosomal structure, location, repeat, or gene density may influence the interchromosomal cross-talk.

Altogether, the examples discussed above strongly support the concept of trans-regulation via interchromosomal contacts and communication-at least at specific loci-and implicate interchromosomal contacts in the regulation of gene expression states that can be inheritable. In addition to the so far better understood cis-interactions on the same chromosome, this interchromosome cross-talk adds an additional layer of complexity to the regulation of DNA-dependent processes. We are currently only at the beginning of understanding the interchromosomal cross-talk, and it will be of central importance to study these interactions in more detail. Live imaging will tell us what the dynamics of these interactions are and whether they are transient or prolonged. The identification and manipulation of DNA elements required for the interaction will allow us to study the functional relevance of the interactions. Many examples of chromosomal interactions are currently just observations of proximity, and many questions are still open. Are the chromosomes indeed in direct physical contact or only in close proximity? Which proteins and protein complexes are mediating these interactions? Are the same proteins involved in loop formation and interchro- mosomal contacts? How are these factors recruited? What is the role of RNA in this process? Is there a feedback mechanism that allows DNA elements to interact with just one other DNA element?

In the future, we will have to search intensively for trans-regulatory elements in the genome and consider that long-range interactions may be targets for gene regulation. Only new high-throughput techniques such as 3C assays coupled with microarrays (Simonis et al. 2006) or direct sequencing will allow an unbiased screen of the genome for DNA loci that contact each other. However, one pitfall of these techniques is that they also capture very transient interactions. A combination with highthroughput FISH could be used to verify these interactions.

\section{Nuclear organization and rearrangements in pluripotent cells}

Pluripotent cells have the potential to self-renew indefinitely and to differentiate into any other cell type. This requires that the pluripotent cells have a nuclear architecture that allows maintenance of the pluripotent state, but which is at the same time so plastic that they can enter any differentiation pathway. As soon as the differentiation pathway is started, lineage specification initiates and a cell-type-specific transcription program starts. Here we discuss the dynamics and plasticity of nuclear organization in ES cells and early mouse embryos compared with lineage-committed cells.

\section{ES cells}

ES cells are enriched in less-compact euchromatin and show a more diffuse heterochromatin structure. Upon differentiation, the heterochromatin rearranges and the number of heterochromatin foci increases (for reviews, see Arney and Fisher 2004; Meshorer and Misteli 2006). The large-scale organization of chromosome territories is similar in ES cells compared with differentiated cells (Wiblin et al. 2005). However, ES cell-specific genes change their position during differentiation-e.g., in humans the NANOG gene relocates from a more peripheral positioning in ES cells to a more central position in B cells-and the OCT4 gene loops out from its chromosome territory in ES cells (Wiblin et al. 2005). This also correlates with an early replication timing of these genes in ES cells compared with a later one in differentiated cells (Perry et al. 2004). In mouse ES cells "bivalent chromatin domains" of large regions of active and repressive histone modifications exist. These domains contain chromatin enriched in H3/K27 methylation, a mark considered specific for repressed, condensed chromatin; within it smaller regions enriched for H3/K4 methylation, a mark for active chromatin, were found (Azuara et al. 2006; Bernstein et al. 2006; Lee et al. 2006). These domains are thought to function, via opposing histone modifications, to silence developmental genes in ES cells while keeping them poised for activation later on. After ES cell differentiation, when genes in these bivalent do- 
mains become turned on, the repressive H3/K27 methylation decreases, whereas the H3/K4 methylation stays (Bernstein et al. 2006; for a recent review about histone modifications in ES cells, see Spivakov and Fisher 2007).

Interestingly, a recent study from the Misteli group (Meshoer et al. 2006) showed that chromatin in ES cells is globally decondensed and contains a high fraction of only loosely bound architectural chromatin proteins, including linker histone $\mathrm{H} 1$ and the HP1 protein. The nature of this pool is still under discussion /Gilbert et al. 2007); it has been shown that this hyperdynamic protein population is a hallmark for truly pluripotent cells, since lineage-committed cells do not have it (Meshorer et al. 2006). Consistent with this, pluripotent cells are enriched in acetylated histones and repressive heterochromatic marks are reduced (Kimura et al. 2004). This open, hyperdynamic chromatin is necessary for ES cell differentiation and was termed "breathing" chromatin (Meshorer et al. 2006). This pool of hyperdynamic chromatin proteins may be needed to establish chromatin domains once cells start lineage-specific gene expression programs by the sequestration of genes into specific active or repressive chromatin domains or proteinaceous bodies (Meshorer et al. 2006). The hyperdynamic, open chromatin in ES cells could allow regulatory factors access to their binding sites and also the rapid activation of lineage-specific gene expression programs.

\section{Early mouse embryo}

Similar to the ES cells, in the early mouse embryo the concept of a "dynamic" chromatin structure, allowing the development of pluripotent cells, has also been described. A recent study linked histone modifications with cell fate in the early embryo. Increasing the level of arginine methylation of histones, generally considered as an activating mark, results in up-regulation of nanog and the "biased" cell fate decision toward the inner cell mass (Torres-Padilla et al. 2007). However, it remains to be studied whether there is any direct link between the activation of particular lineage restriction genes during development and this chromatin enriched in active marks, and what the exact role of the nuclear organization in these embryonic cells is.

The nuclear organization in the mouse embryo during preimplantation development (in the zygote and during the first rounds of cleavage divisions) displays particular features that are dynamic and dramatically distinctive from somatic cells (Morgan et al. 2005); e.g., a particular organization and relocalization of the centromeric repeats within the nucleus. It is likely that these features are necessary for the reprogramming of the chromatin that has to occur in the embryo after fertilization. A detailed analysis of the localization of the centromeric major and minor satellite repeats (forming the so-called chromocenter) in the paternal and maternal genomes after fertilization has revealed that the nuclear organization of the centromeric satellite regions becomes remodeled in the space of a few hours (Probst et al. 2007). The major satellites move toward the center of the pronuclei and adopt a special ring-like structure around the nucleolar-like bodies, which are spherical structures considered as the precursors of the nucleoli. This relocation of the repeats is accompanied by a switch in replication timing (Martin et al. 2006) and occurs at the same time as the transcriptional activation of the silenced embryonic genome. The consequence of this organization is that the pericentromeric regions of different chromosomes come in physical proximity, potentially allowing some kind of cross-talk. It is interesting to note that not all of the chromosomes adopt this particular configuration of the centromeres, as a prochromocenter-like structure prevails specifically in the female pronucleus (Probst et al. 2007). Upon cell differentiation during the formation of the blastocyst, the centromeric repeats move and adopt a somatic-like organization (Martin et al. 2006). The significance for normal development and the molecular mechanism behind this particular relocalization of the centromeres remains to be determined. However, in cloned embryos derived from somatic nuclear transfer, the somatic chromocenter configuration of the donor nucleus is rapidly reverted (Martin et al. 2006). This suggests that the relocalization of huge genomic regions and the acquisition of this specific embryonic chromocenter configuration are required for reprogramming.

Interestingly, pluripotent cells seem to require a dynamic, active nuclear organization enabling maintenance of the pluripotent state and the potential to differentiate into any lineage. The intense chromatin reprogramming in early mouse embryos that is necessary for the plasticity of the embryo involves histone modifications, nuclear repositioning, and in particular, reorganization on a more global level compared with the chromatin movements involved in the activation of specific genes. Currently, our knowledge about the contribution of nuclear architecture to pluripotency is still limited. To gain insight into this, it will be important to compare the nuclear organization and dynamics of pluripotent and lineage-committed cells in more detail.

\section{Perspectives}

The understanding of the relationship between nuclear architecture, genome organization, and gene expression will be aided by the application of new imaging techniques that include improvements of the resolution, time-lapse, and live cell imaging. The advent of highthroughput analysis of histone modifications has provided us with a genome-wide map for many chromatin modifications. Although these data allow for a detailed knowledge of chromatin states, we still have very limited insight into the causal relationship between chromatin modification, higher-order chromatin organization, subnuclear gene localization, and gene expression. In particular, the clarification of the cause-effect relationship of nuclear organization and the function of the genome represents one of the most important future challenges. Further experiments are needed to determine whether the spatial organization of the nucleus is a con- 
sequence of genome organization, chromatin modifications, and DNA-based processes, or whether nuclear architecture is an important determinant of the function of the genome. For example, the concept of self-organization of nuclear structures and subcompartments by specific DNA sequences is supported by the extensive analysis of the ribosomal genes and their role in the genesis of the nucleolus. However, this model needs further validation, and its generality has to be addressed, including whether and to what extent such genome-driven nuclear self-organization plays a role at other gene loci. Another important future avenue will be the identification of proteins that, like CTCF, mediate intra- and/or interchromosomal interactions. A molecular characterization of these proteins and their multiprotein complexes will help to understand the coordinate expression of genes that do not reside in gene clusters. Finally, the question of the molecular forces in the nucleus that mediate chromatin mobility will be of utmost importance for our understanding of the dynamics of the genome. With the advent of innovative techniques and interdisciplinary approaches, combined with the enthusiasm of this field of research, we can expect fascinating future insight into a central biological problem.

\section{Acknowledgments}

We thank Dr. Patrick Heun for critical reading of the manuscript. Research in the R.S. laboratory is supported by a HFSP career development award, the Epigenome Network of Excellence, the DFG, and the MPG. Research in the R.G. laboratory is supported by the MPG and the DFG.

\section{References}

Akhtar, A. and Gasser, S.M. 2007. The nuclear envelope and transcriptional control. Nat. Rev. Genet. 8: 507-517.

Andrulis, E.D., Neiman, A.M., Zappulla, D.C., and Sternglanz, R. 1998. Perinuclear localization of chromatin facilitates transcriptional silencing. Nature 394: 592-595.

Andrulis, E.D., Zappulla, D.C., Ansari, A., Perrod, S., Laiosa, C.V., Gartenberg, M.R., and Sternglanz, R. 2002. Esc1, a nuclear periphery protein required for Sir4-based plasmid anchoring and partitioning. Mol. Cell. Biol. 22: 8292-8301.

Arney, K.L. and Fisher, A.G. 2004. Epigenetic aspects of differentiation. J. Cell Sci. 117: 4355-4363.

Azuara, V., Perry, P., Sauer, S., Spivakov, M., Jorgensen, H.F., John, R.M., Gouti, M., Casanova, M., Warnes, G., Merkenschlager, M., et al. 2006. Chromatin signatures of pluripotent cell lines. Nat. Cell Biol. 8: 532-538.

Bacher, C.P., Guggiari, M., Brors, B., Augui, S., Clerc, P., Avner, P., Eils, R., and Heard, E. 2006. Transient colocalization of $\mathrm{X}$-inactivation centres accompanies the initiation of $\mathrm{X}$ inactivation. Nat. Cell Biol. 8: 293-299.

Bannister, A.J., Zegerman, P., Partridge, J.F., Miska, E.A., Thomas, J.O., Allshire, R.C., and Kouzarides, T. 2001. Selective recognition of methylated lysine 9 on histone $\mathrm{H} 3$ by the HP1 chromo domain. Nature 410: 120-124.

Bannister, A.J., Schneider, R., Myers, F.A., Thorne, A.W., CraneRobinson, C., and Kouzarides, T. 2005. Spatial distribution of di- and tri-methyl lysine 36 of histone $\mathrm{H} 3$ at active genes. J. Biol. Chem. 280: 17732-17736.
Bantignies, F., Grimaud, C., Lavrov, S., Gabut, M., and Cavalli, G. 2003. Inheritance of Polycomb-dependent chromosomal interactions in Drosophila. Genes \& Dev. 17: 24062420.

Barski, A., Cuddapah, S., Cui, K., Roh, T.Y., Schones, D.E., Wang, Z., Wei, G., Chepelev, I., and Zhao, K. 2007. Highresolution profiling of histone methylations in the human genome. Cell 129: 823-837.

Bartlett, J., Blagojevic, J., Carter, D., Eskiw, C., Fromaget, M., Job, C., Shamsher, M., Trindade, I.F., Xu, M., and Cook, P.R. 2006. Specialized transcription factories. Biochem. Soc. Symp. 2006: 67-75.

Bassing, C.H., Swat, W., and Alt, F.W. 2002. The mechanism and regulation of chromosomal $\mathrm{V}(\mathrm{D}) \mathrm{J}$ recombination. Cell 109 (Suppl.): S45-S55. doi: 10.1016/S0092-8674(02)0067-X.

Bernstein, B.E., Mikkelsen, T.S., Xie, X., Kamal, M., Huebert, D.J., Cuff, J., Fry, B., Meissner, A., Wernig, M., Plath, K., et al. 2006. A bivalent chromatin structure marks key developmental genes in embryonic stem cells. Cell 125: 315-326.

Blobel, G. 1985. Gene gating: A hypothesis. Proc. Nat1. Acad. Sci. 82: 8527-8529.

Boggs, B.A., Connors, B., Sobel, R.E., Chinault, A.C., and Allis, C.D. 1996. Reduced levels of histone H3 acetylation on the inactive $\mathrm{X}$ chromosome in human females. Chromosoma 105: 303-309.

Boggs, B.A., Cheung, P., Heard, E., Spector, D.L., Chinault, A.C., and Allis, C.D. 2002. Differentially methylated forms of histone $\mathrm{H} 3$ show unique association patterns with inactive human X chromosomes. Nat. Genet. 30: 73-76.

Borden, J. and Manuelidis, L. 1988. Movement of the X chromosome in epilepsy. Science 242: 1687-1691.

Boyle, S., Gilchrist, S., Bridger, J.M., Mahy, N.L., Ellis, J.A., and Bickmore, W.A. 2001. The spatial organization of human chromosomes within the nuclei of normal and emerin-mutant cells. Hum. Mol. Genet. 10: 211-219.

Branco, M.R. and Pombo, A. 2006. Intermingling of chromosome territories in interphase suggests role in translocations and transcription-dependent associations. PLOS Biol. 4: e138. doi: 10.1371/journal.pbio.0040138.

Bridger, J.M., Boyle, S., Kill, I.R., and Bickmore, W.A. 2000. Re-modelling of nuclear architecture in quiescent and senescent human fibroblasts. Curr. Biol. 10: 149-152.

Brown, C.J., Lafreniere, R.G., Powers, V.E., Sebastio, G., Ballabio, A., Pettigrew, A.L., Ledbetter, D.H., Levy, E., Craig, I.W., and Willard, H.F. 1991. Localization of the X inactivation centre on the human $\mathrm{X}$ chromosome in $\mathrm{Xq} 13$. Nature 349: 82-84.

Brown, K.E., Amoils, S., Horn, J.M., Buckle, V.J., Higgs, D.R., Merkenschlager, M., and Fisher, A.G. 2001. Expression of $\alpha$ and $\beta$-globin genes occurs within different nuclear domains in haemopoietic cells. Nat. Cell Biol. 3: 602-606.

Brown, J.M., Leach, J., Reittie, J.E., Atzberger, A., Lee-Prudhoe, J., Wood, W.G., Higgs, D.R., Iborra, F.J., and Buckle, V.J. 2006. Coregulated human globin genes are frequently in spatial proximity when active. J. Cell Biol. 172: 177-187.

Cabal, G.G., Genovesio, A., Rodriguez-Navarro, S., Zimmer, C., Gadal, O., Lesne, A., Buc, H., Feuerbach-Fournier, F., OlivoMarin, J.C., Hurt, E.C., et al. 2006. SAGA interacting factors confine sub-diffusion of transcribed genes to the nuclear envelope. Nature 441: 770-773.

Cai, S., Lee, C.C., and Kohwi-Shigematsu, T. 2006. SATB1 packages densely looped, transcriptionally active chromatin for coordinated expression of cytokine genes. Nat. Genet. 38: 1278-1288.

Carrel, L. 2006. Molecular biology. 'X'-rated chromosomal rendezvous. Science 311: 1107-1109. 
Casolari, J.M., Brown, C.R., Komili, S., West, J., Hieronymus, H., and Silver, P.A. 2004. Genome-wide localization of the nuclear transport machinery couples transcriptional status and nuclear organization. Cell 117: 427-439.

Chambeyron, S. and Bickmore, W.A. 2004. Chromatin decondensation and nuclear reorganization of the HoxB locus upon induction of transcription. Genes \& Dev. 18: 1119-1130.

Chaumeil, J., Le Baccon, P., Wutz, A., and Heard, E. 2006. A novel role for Xist RNA in the formation of a repressive nuclear compartment into which genes are recruited when silenced. Genes \& Dev. 20: 2223-2237.

Chowdhury, D. and Sen, R. 2001. Stepwise activation of the immunoglobulin $\mu$ heavy chain gene locus. $E M B O J$. 20: 6394-6403.

Chubb, J.R., Boyle, S., Perry, P., and Bickmore, W.A. 2002. Chromatin motion is constrained by association with nuclear compartments in human cells. Curr. Biol. 12: 439-445.

Clemson, C.M., Hall, L.L., Byron, M., McNeil, J., and Lawrence, J.B. 2006. The $\mathrm{X}$ chromosome is organized into a gene-rich outer rim and an internal core containing silenced nongenic sequences. Proc. Natl. Acad. Sci. 103: 7688-7693.

Cook, P.R. 1999. The organization of replication and transcription. Science 284: 1790-1795.

Couture, J.F. and Trievel, R.C. 2006. Histone-modifying enzymes: Encrypting an enigmatic epigenetic code. Curr. Opin. Struct. Biol. 16: 753-760.

Cremer, T., Cremer, C., Baumann, H., Luedtke, E.K., Sperling, K., Teuber, V., and Zorn, C. 1982. Rabl's model of the interphase chromosome arrangement tested in Chinese hamster cells by premature chromosome condensation and laser-UVmicrobeam experiments. Hum. Genet. 60: 46-56.

Cremer, T., Lichter, P., Borden, J., Ward, D.C., and Manuelidis, L. 1988. Detection of chromosome aberrations in metaphase and interphase tumor cells by in situ hybridization using chromosome-specific library probes. Hum. Genet. 80: 235246.

Cremer, M., von Hase, J., Volm, T., Brero, A., Kreth, G., Walter, J., Fischer, C., Solovei, I., Cremer, C., and Cremer, T. 2001. Non-random radial higher-order chromatin arrangements in nuclei of diploid human cells. Chromosome Res. 9: 541-567.

Cremer, T., Cremer, M., Dietzel, S., Muller, S., Solovei, I., and Fakan, S. 2006. Chromosome territories-A functional nuclear landscape. Curr. Opin. Cell Biol. 18: 307-316.

Croft, J.A., Bridger, J.M., Boyle, S., Perry, P., Teague, P., and Bickmore, W.A. 1999. Differences in the localization and morphology of chromosomes in the human nucleus. J. Cell Biol. 145: 1119-1131.

Davie, J.R. 1995. The nuclear matrix and the regulation of chromatin organization and function. Int. Rev. Cytol. 162A: 191250.

Davie, J.R. and Candido, E.P. 1978. Acetylated histone H4 is preferentially associated with template-active chromatin. Proc. Nat1. Acad. Sci. 75: 3574-3577.

Dekker, J. 2006. The three 'C's of chromosome conformation capture: Controls, controls, controls. Nat. Methods 3: 17-21.

Duncan, I.W. 2002. Transvection effects in Drosophila. Annu. Rev. Genet. 36: 521-556.

The ENCODE Project Consortium. 2007. Identification and analysis of functional elements in $1 \%$ of the human genome by the ENCODE pilot project. Nature 447: 799-816.

Faro-Trindade, I. and Cook, P.R. 2006. Transcription factories: Structures conserved during differentiation and evolution. Biochem. Soc. Trans. 34: 1133-1137.

Foster, S.L., Hargreaves, D.C., and Medzhitov, R. 2007. Genespecific control of inflammation by TLR-induced chromatin modifications. Nature 447: 972-978.
Francis, N.J., Kingston, R.E., and Woodcock, C.L. 2004. Chromatin compaction by a polycomb group protein complex. Science 306: 1574-1577.

Fuss, S.H., Omura, M., and Mombaerts, P. 2007. Local and cis effects of the $\mathrm{H}$ element on expression of odorant receptor genes in mouse. Cell 130: 373-384.

Fuxa, M., Skok, J., Souabni, A., Salvagiotto, G., Roldan, E., and Busslinger, M. 2004. Pax5 induces V-to-DJ rearrangements and locus contraction of the immunoglobulin heavy-chain gene. Genes \& Dev. 18: 411-422.

Gartenberg, M.R., Neumann, F.R., Laroche, T., Blaszczyk, M., and Gasser, S.M. 2004. Sir-mediated repression can occur independently of chromosomal and subnuclear contexts. Cell 119: 955-967.

Gilbert, N., Boyle, S., Fiegler, H., Woodfine, K., Carter, N.P., and Bickmore, W.A. 2004. Chromatin architecture of the human genome: Gene-rich domains are enriched in open chromatin fibers. Cell 118: 555-566.

Gilbert, N., Thomson, I., Boyle, S., Allan, J., Ramsahoye, B., and Bickmore, W.A. 2007. DNA methylation affects nuclear organization, histone modifications, and linker histone binding but not chromatin compaction. J. Cell Biol. 177: 401411.

Goldmit, M., Ji, Y., Skok, J., Roldan, E., Jung, S., Cedar, H., and Bergman, Y. 2005. Epigenetic ontogeny of the Igk locus during B cell development. Nat. Immunol. 6: 198-203.

Grimaud, C., Bantignies, F., Pal-Bhadra, M., Ghana, P., Bhadra, U., and Cavalli, G. 2006. RNAi components are required for nuclear clustering of Polycomb group response elements. Cell 124: 957-971.

Guenther, M.G., Levine, S.S., Boyer, L.A., Jaenisch, R., and Young, R.A. 2007. A chromatin landmark and transcription initiation at most promoters in human cells. Cell 130: 7788.

Hawwari, A. and Krangel, M.S. 2005. Regulation of TCR $\delta$ and $\alpha$ repertoires by local and long-distance control of variable gene segment chromatin structure. J. Exp. Med. 202: 467472

Heard, E. and Bickmore, W. 2007. The ins and outs of gene regulation and chromosome territory organisation. Curr. Opin. Cell. Biol. 19: 311-316.

Heard, E., Rougeulle, C., Arnaud, D., Avner, P., Allis, C.D., and Spector, D.L. 2001. Methylation of histone H3 at Lys-9 is an early mark on the $\mathrm{X}$ chromosome during $\mathrm{X}$ inactivation. Cell 107: 727-738.

Heitz, E. 1928. Das Heterochromatin der Moose. Jarbuch Wiss. Bot. 69: 762-780.

Heun, P. 2007. SUMOrganization of the nucleus. Curr. Opin. Cell Biol. 19: 350-355.

Hewitt, S.L., High, F.A., Reiner, S.L., Fisher, A.G., and Merkenschlager, M. 2004. Nuclear repositioning marks the selective exclusion of lineage-inappropriate transcription factor loci during $\mathrm{T}$ helper cell differentiation. Eur. J. Immunol. 34: 3604-3613.

Hopmann, R., Duncan, D., and Duncan, I. 1995. Transvection in the iab-5,6,7 region of the bithorax complex of Drosophila: Homology independent interactions in trans. Genetics 139: 815-833.

Iborra, F.J., Pombo, A., McManus, J., Jackson, D.A., and Cook, P.R. 1996. The topology of transcription by immobilized polymerases. Exp. Cell Res. 229: 167-173.

Ishii, K., Arib, G., Lin, C., Van Houwe, G., and Laemmli, U.K. 2002. Chromatin boundaries in budding yeast: The nuclear pore connection. Cell 109: 551-562.

Jackson, D.A. and Cook, P.R. 1985. Transcription occurs at a nucleoskeleton. EMBO J. 4: 919-925. 
Jackson, D.A., Iborra, F.J., Manders, E.M., and Cook, P.R. 1998. Numbers and organization of RNA polymerases, nascent transcripts, and transcription units in HeLa nuclei. Mol. Biol. Cell 9: 1523-1536.

Jeppesen, P. and Turner, B.M. 1993. The inactive X chromosome in female mammals is distinguished by a lack of histone $\mathrm{H} 4$ acetylation, a cytogenetic marker for gene expression. Cell 74: 281-289.

Kimura, H., Tada, M., Nakatsuji, N., and Tada, T. 2004. Histone code modifications on pluripotential nuclei of reprogrammed somatic cells. Mol. Cell. Biol. 24: 5710-5720.

Kosak, S.T., Skok, J.A., Medina, K.L., Riblet, R., Le Beau, M.M., Fisher, A.G., and Singh, H. 2002. Subnuclear compartmentalization of immunoglobulin loci during lymphocyte development. Science 296: 158-162.

Kouzarides, T. 2007. Chromatin modifications and their function. Cell 128: 693-705.

Kumar, P.P., Bischof, O., Purbey, P.K., Notani, D., Urlaub, H., Dejean, A., and Galande, S. 2007. Functional interaction between PML and SATB1 regulates chromatin-loop architecture and transcription of the MHC class I locus. Nat. Cell Biol. 9: 45-56.

Lachner, M., O'Carroll, D., Rea, S., Mechtler, K., and Jenuwein, T. 2001. Methylation of histone H3 lysine 9 creates a binding site for HP1 proteins. Nature 410: 116-120.

Lanctot, C., Kaspar, C., and Cremer, T. 2007. Positioning of the mouse Hox gene clusters in the nuclei of developing embryos and differentiating embryoid bodies. Exp. Cell Res. 313: 1449-1459.

Lee, J.T. 2005. Regulation of X-chromosome counting by Tsix and Xite sequences. Science 309: 768-771.

Lee, T.I., Jenner, R.G., Boyer, L.A., Guenther, M.G., Levine, S.S., Kumar, R.M., Chevalier, B., Johnstone, S.E., Cole, M.F., Isono, K., et al. 2006. Control of developmental regulators by Polycomb in human embryonic stem cells. Cell 125: 301313.

Lei, E.P. and Corces, V.G. 2006. A long-distance relationship between RNAi and Polycomb. Cell 124: 886-888.

Lewis, E.B. 1954. The theory and application of a new method of detecting chromosomal rearrangements in Drosophila melanogaster. Am. Nat. 88: 225-239.

Ling, J.Q., Li, T., Hu, J.F., Vu, T.H., Chen, H.L., Qiu, X.W., Cherry, A.M., and Hoffman, A.R. 2006. CTCF mediates interchromosomal colocalization between Igf2/H19 and Wsb1/Nf1. Science 312: 269-272.

Litt, M.D., Simpson, M., Gaszner, M., Allis, C.D., and Felsenfeld, G. 2001. Correlation between histone lysine methylation and developmental changes at the chicken $\beta$-globin locus. Science 293: 2453-2455.

Liu, J., Lee, K.K., Segura-Totten, M., Neufeld, E., Wilson, K.L., and Gruenbaum, Y. 2003. MAN1 and emerin have overlapping function(s) essential for chromosome segregation and cell division in Caenorhabditis elegans. Proc. Natl. Acad. Sci. 100: 4598-4603.

Lomvardas, S., Barnea, G., Pisapia, D.J., Mendelsohn, M., Kirkland, J., and Axel, R. 2006. Interchromosomal interactions and olfactory receptor choice. Cell 126: 403-413.

Mahy, N.L., Perry, P.E., and Bickmore, W.A. 2002a. Gene density and transcription influence the localization of chromatin outside of chromosome territories detectable by FISH. J. Cell Biol. 159: 753-763.

Mahy, N.L., Perry, P.E., Gilchrist, S., Baldock, R.A., and Bickmore, W.A. 2002b. Spatial organization of active and inactive genes and noncoding DNA within chromosome territories. J. Cell Biol. 157: 579-589.

Maillet, L., Boscheron, C., Gotta, M., Marcand, S., Gilson, E., and Gasser, S.M. 1996. Evidence for silencing compartments within the yeast nucleus: A role for telomere proximity and Sir protein concentration in silencer-mediated repression. Genes \& Dev. 10: 1796-1811.

Makatsori, D., Kourmouli, N., Polioudaki, H., Shultz, L.D., McLean, K., Theodoropoulos, P.A., Singh, P.B., and Georgatos, S.D. 2001. The inner nuclear membrane protein lamin B receptor forms distinct microdomains and links epigenetically marked chromatin to the nuclear envelope. J. Biol. Chem. 279: 25567-25573.

Marahrens, Y. 1999. X-inactivation by chromosomal pairing events. Genes \& Dev. 13: 2624-2632.

Markiewicz, E., Tilgner, K., Barker, N., van de Wetering, M., Clevers, H., Dorobek, M., Hausmanowa-Petrusewicz, I., Ramaekers, F.C., Broers, J.L., Blankesteijn, W.M., et al. 2006. The inner nuclear membrane protein emerin regulates $\beta$ catenin activity by restricting its accumulation in the nucleus. EMBO T. 25: 3275-3285.

Marshall, W.F., Straight, A., Marko, J.F., Swedlow, J., Dernburg, A., Belmont, A., Murray, A.W., Agard, D.A., and Sedat, J.W. 1997. Interphase chromosomes undergo constrained diffusional motion in living cells. Curr. Biol. 7: 930-939.

Martin, C., Beaujean, N., Brochard, V., Audouard, C., Zink, D., and Debey, P. 2006. Genome restructuring in mouse embryos during reprogramming and early development. Dev. Biol. 292: 317-332.

Mermoud, J.E., Costanzi, C., Pehrson, J.R., and Brockdorff, N. 1999. Histone macroH2A1.2 relocates to the inactive $\mathrm{X}$ chromosome after initiation and propagation of X-inactivation. J. Cell Biol. 147: 1399-1408.

Mermoud, J.E., Popova, B., Peters, A.H., Jenuwein, T., and Brockdorff, N. 2002. Histone H3 lysine 9 methylation occurs rapidly at the onset of random $\mathrm{X}$ chromosome inactivation. Curr. Biol. 12: 247-251.

Meshorer, E. and Misteli, T. 2006. Chromatin in pluripotent embryonic stem cells and differentiation. Nat. Rev. Mol. Cell Biol. 7: 540-546.

Meshorer, E., Yellajoshula, D., George, E., Scambler, P.J., Brown, D.T., and Misteli, T. 2006. Hyperdynamic plasticity of chromatin proteins in pluripotent embryonic stem cells. Dev. Cell 10: 105-116.

Mirsky, A.E. and Allfrey, V. 1960. Biochemical activities of the cell nucleus. Dis. Nerv. Syst. 21 (Suppl.): 23-28.

Misteli, T. 2007. Beyond the sequence: Cellular organization of genome function. Cell 128: 787-800.

Morey, C., Da Silva, N.R., Perry, P., and Bickmore, W.A. 2007. Nuclear reorganisation and chromatin decondensation are conserved, but distinct, mechanisms linked to Hox gene activation. Development 134: 909-919.

Morgan, H.D., Santos, F., Green, K., Dean, W., and Reik, W. 2005. Epigenetic reprogramming in mammals. Hum. Mol. Genet. 14: R47-R58. doi: 10.1093/hmg/ddil14.

Mostoslavsky, R., Singh, N., Tenzen, T., Goldmit, M., Gabay, C., Elizur, S., Qi, P., Reubinoff, B.E., Chess, A., Cedar, H., et al. 2001. Asynchronous replication and allelic exclusion in the immune system. Nature 414: 221-225.

Muller, W.G., Rieder, D., Karpova, T.S., John, S., Trajanoski, Z., and McNally, J.G. 2007. Organization of chromatin and histone modifications at a transcription site. J. Cell Biol. 177: 957-967.

Norris, D.P., Brockdorff, N., and Rastan, S. 1991. Methylation status of CpG-rich islands on active and inactive mouse $\mathrm{X}$ chromosomes. Mamm. Genome 1: 78-83.

Osborne, C.S., Chakalova, L., Brown, K.E., Carter, D., Horton, A., Debrand, E., Goyenechea, B., Mitchell, J.A., Lopes, S., Reik, W., et al. 2004. Active genes dynamically colocalize to 
shared sites of ongoing transcription. Nat. Genet. 36: 10651071.

Osborne, C.S., Chakalova, L., Mitchell, J.A., Horton, A., Wood, A.L., Bolland, D.J., Corcoran, A.E., and Fraser, P. 2007. Myc dynamically and preferentially relocates to a transcription factory occupied by Igh. PLOS Biol. 5: e192. doi: 10.1371/ journal.pbio.0050192.

Pan, D., Estevez-Salmeron, L.D., Stroschein, S.L., Zhu, X., He, J., Zhou, S., and Luo, K. 2005. The integral inner nuclear membrane protein MAN1 physically interacts with the R-Smad proteins to repress signaling by the transforming growth factor- $\beta$ superfamily of cytokines. J. Biol. Chem. 280: 15992-16001.

Perry, P., Sauer, S., Billon, N., Richardson, W.D., Spivakov, M., Warnes, G., Livesey, F.J., Merkenschlager, M., Fisher, A.G., and Azuara, V. 2004. A dynamic switch in the replication timing of key regulator genes in embryonic stem cells upon neural induction. Cell Cycle 3: 1645-1650.

Peters, A.H., O'Carroll, D., Scherthan, H., Mechtler, K., Sauer, S., Schofer, C., Weipoltshammer, K., Pagani, M., Lachner, M., Kohlmaier, A., et al. 2001. Loss of the Suv39h histone methyltransferases impairs mammalian heterochromatin and genome stability. Cell 107: 323-337.

Pickersgill, H., Kalverda, B., de Wit, E., Talhout, W., Fornerod, M., and van Steensel, B. 2006. Characterization of the Drosophila melanogaster genome at the nuclear lamina. Nat. Genet. 38: 1005-1014.

Pinkel, D., Landegent, J., Collins, C., Fuscoe, J., Segraves, R., Lucas, J., and Gray, J. 1988. Fluorescence in situ hybridization with human chromosome-specific libraries: Detection of trisomy 21 and translocations of chromosome 4. Proc. Nat1. Acad. Sci. 85: 9138-9142.

Pirrotta, V. 1999. Transvection and chromosomal trans-interaction effects. Biochim. Biophys. Acta 1424: M1-M8. doi: 10.1016/S0304-419(99)00019-0.

Plath, K., Fang, J., Mlynarczyk-Evans, S.K., Cao, R., Worringer, K.A., Wang, H., de la Cruz, C.C., Otte, A.P., Panning, B., and Zhang, Y. 2003. Role of histone H3 lysine 27 methylation in $\mathrm{X}$ inactivation. Science 300: 131-135.

Polioudaki, H., Kourmouli, N., Drosou, V., Bakou, A., Theodoropoulos, P.A., Singh, P.B, Giannakouros, T., and Georgatos, S.D. 2001. Histones H3/H4 form a tight complex with the inner nuclear membrane protein LBR and heterochromatin protein 1. EMBO Rep. 2: 920-925.

Pombo, A., Jackson, D.A., Hollinshead, M., Wang, Z., Roeder, R.G., and Cook, P.R. 1999. Regional specialization in human nuclei: Visualization of discrete sites of transcription by RNA polymerase III. EMBO J. 18: 2241-2253.

Probst, A.V., Santos, F., Reik, W., Almouzni, G., and Dean, W. 2007. Structural differences in centromeric heterochromatin are spatially reconciled on fertilisation in the mouse zygote. Chromosoma 116: 403-415.

Ragoczy, T., Bender, M.A., Telling, A., Byron, R., and Groudine, M. 2006. The locus control region is required for association of the murine $\beta$-globin locus with engaged transcription factories during erythroid maturation. Genes \& Dev. 20: 14471457.

Raska, I., Shaw, P.J., and Cmarko, D. 2006. Structure and function of the nucleolus in the spotlight. Curr. Opin. Cell Biol. 18: $325-334$.

Rodriguez-Navarro, S., Fischer, T., Luo, M.J., Antunez, O., Brettschneider, S., Lechner, J., Perez-Ortin, J.E., Reed, R., and Hurt, E. 2004. Sus1, a functional component of the SAGA histone acetylase complex and the nuclear pore-associated mRNA export machinery. Cell 116: 75-86.

Roldan, E., Fuxa, M., Chong, W., Martinez, D., Novatchkova,
M., Busslinger, M., and Skok, J.A. 2005. Locus 'decontraction' and centromeric recruitment contribute to allelic exclusion of the immunoglobulin heavy-chain gene. Nat. Immunol. 6: 31-41.

Ronshaugen, M. and Levine, M. 2004. Visualization of transhomolog enhancer-promoter interactions at the Abd-B Hox locus in the Drosophila embryo. Dev. Cell 7: 925-932.

Sayegh, C., Jhunjhunwala, S., Riblet, R., and Murre, C. 2005. Visualization of looping involving the immunoglobulin heavy-chain locus in developing B cells. Genes \& Dev. 19: 322-327.

Schirmer, E.C. and Foisner, R. 2007. Proteins that associate with lamins: Many faces, many functions. Exp. Cell Res. 313: 2167-2179.

Schmid, M., Arib, G., Laemmli, C., Nishikawa, J., Durussel, T., and Laemmli, U.K. 2006. Nup-PI: The nucleopore-promoter interaction of genes in yeast. Mol. Cell 21: 379-391.

Schneider, R., Bannister, A.J., and Kouzarides, T. 2002. Unsafe SETs: Histone lysine methyltransferases and cancer. Trends Biochem. Sci. 27: 396-402.

Schneider, R., Bannister, A.J., Myers, F.A., Thorne, A.W., CraneRobinson, C., and Kouzarides, T. 2004. Histone H3 lysine 4 methylation patterns in higher eukaryotic genes. Nat. Cell Biol. 6: 73-77.

Schwaiger, M. and Schubeler, D. 2006. A question of timing: Emerging links between transcription and replication. Curr. Opin. Genet. Dev. 16: 177-183.

Seeler, J.S. and Dejean, A. 2003. Nuclear and unclear functions of SUMO. Nat. Rev. Mol. Cell Biol. 4: 690-699.

Shi, Y., Lan, F., Matson, C., Mulligan, P., Whetstine, J.R., Cole, P.A., Casero, R.A., and Shi, Y. 2004. Histone demethylation mediated by the nuclear amine oxidase homolog LSD1. Cell 119: 941-953.

Silva, J., Mak, W., Zvetkova, I., Appanah, R., Nesterova, T.B., Webster, Z., Peters, A.H., Jenuwein, T., Otte, A.P., and Brockdorff, N. 2003. Establishment of histone H3 methylation on the inactive $\mathrm{X}$ chromosome requires transient recruitment of Eed-Enxl polycomb group complexes. Dev. Cell 4: 481-495.

Simonis, M., Klous, P., Splinter, E., Moshkin, Y., Willemsen, R., de Wit, E., van Steensel, B., and de Laat, W. 2006. Nuclear organization of active and inactive chromatin domains uncovered by chromosome conformation capture-on-chip (4C). Nat. Genet. 38: 1348-1354.

Skok, J.A., Gisler, R., Novatchkova, M., Farmer, D., de Laat, W., and Busslinger, M. 2007. Reversible contraction by looping of the Tcra and Tcrb loci in rearranging thymocytes. Nat. Immunol. 8: 378-387.

Spector, D.L. 2003. The dynamics of chromosome organization and gene regulation. Annu. Rev. Biochem. 2: 573-608.

Spector, D.L. 2004. Stopping for FISH and chips along the chromatin fiber superhighway. Mol. Cell 15: 844-846.

Spilianakis, C.G., Lalioti, M.D., Town, T., Lee, G.R., and Flavell, R.A. 2005. Interchromosomal associations between alternatively expressed loci. Nature 435: 637-645.

Spivakov, M. and Fisher, A.G. 2007. Epigenetic signatures of stem-cell identity. Nat. Rev. Genet. 8: 263-271.

Strahl, B.D. and Allis, C.D. 2000. The language of covalent histone modifications. Nature 403: 41-45.

Su, I.H., Basavaraj, A., Krutchinsky, A.N., Hobert, O., Ullrich, A., Chait, B.T., and Tarakhovsky, A. 2003. Ezh2 controls B cell development through histone H3 methylation and Igh rearrangement. Nat. Immunol. 4: 124-131.

Su, I.H., Dobenecker, M.W., Dickinson, E., Oser, M., Basavaraj, A., Marqueron, R., Viale, A., Reinberg, D., Wulfing, C., and Tarakhovsky, A. 2005. Polycomb group protein ezh2 con- 
trols actin polymerization and cell signaling. Cell 121: 425436.

Taddei, A., Maison, C., Roche, D., and Almouzni, G. 2001. Reversible disruption of pericentric heterochromatin and centromere function by inhibiting deacetylases. Nat. Cell Biol. 3: $114-120$

Thomson, I., Gilchrist, S., Bickmore, W.A., and Chubb, J.R. 2004. The radial positioning of chromatin is not inherited through mitosis but is established de novo in early G1. Curr. Biol. 14: 166-172.

Torres-Padilla, M.E., Parfitt, D.E., Kouzarides, T., and ZernickaGoetz, M. 2007. Histone arginine methylation regulates pluripotency in the early mouse embryo. Nature 445: 214-218.

Turner, B.M. 1993. Decoding the nucleosome. Cell 75: 5-8.

Turner, B.M. 2007. Defining an epigenetic code. Nat. Cell Biol. 9: $2-6$.

Vazquez, J., Belmont, A.S., and Sedat, J.W. 2001. Multiple regimes of constrained chromosome motion are regulated in the interphase Drosophila nucleus. Curr. Biol. 11: 12271239.

Volpi, E.V., Chevret, E., Jones, T., Vatcheva, R., Williamson, J., Beck, S., Campbell, R.D., Goldsworthy, M., Powis, S.H., Ragoussis, J., et al. 2000. Large-scale chromatin organization of the major histocompatibility complex and other regions of human chromosome 6 and its response to interferon in interphase nuclei. J. Cell Sci. 113: 1565-1576.

Wiblin, A.E., Cui, W., Clark, A.J., and Bickmore, W.A. 2005. Distinctive nuclear organisation of centromeres and regions involved in pluripotency in human embryonic stem cells. $J$. Cell Sci. 118: 3861-3868.

Williams, R.R., Azuara, V., Perry, P., Sauer, S., Dvorkina, M., Jorgensen, H., Roix, J., McQueen, P., Misteli, T., Merkenschlager, M., et al. 2006. Neural induction promotes largescale chromatin reorganisation of the Mash1 locus. J. Cell Sci. 119: 132-140.

Wilmut, I. and Campbell, K.H. 1998. Quiescence in nuclear transfer. Science 281: 1611.

Wurtele, H. and Chartrand, P. 2006. Genome-wide scanning of HoxB1-associated loci in mouse ES cells using an openended chromosome conformation capture methodology. Chromosome Res. 14: 477-495.

$\mathrm{Xu}$, N., Tsai, C.L., and Lee, J.T. 2006. Transient homologous chromosome pairing marks the onset of $\mathrm{X}$ inactivation. Science 311: 1149-1152.

Yin, H., Wang, M.D., Svoboda, K., Landick, R., Block, S.M., and Gelles, J. 1995. Transcription against an applied force. Science 270: 1653-1657.

Zhang, L.F., Huynh, K.D., and Lee, J.T. 2007. Perinucleolar targeting of the inactive $\mathrm{X}$ during $\mathrm{S}$ phase: Evidence for a role in the maintenance of silencing. Cell 129: 693-706.

Zhao, Z., Tavoosidana, G., Sjolinder, M., Gondor, A., Mariano, P., Wang, S., Kanduri, C., Lezcano, M., Sandhu, K.S., Singh, U., et al. 2006. Circular chromosome conformation capture (4C) uncovers extensive networks of epigenetically regulated intra- and interchromosomal interactions. Nat. Genet. 38: 1341-1347.

Zhou, J. and Levine, M. 1999. A novel cis-regulatory element, the PTS, mediates an anti-insulator activity in the Drosophila embryo. Cell 99: 567-575.

Zhou, J., Ashe, H., Burks, C., and Levine, M. 1999. Characterization of the transvection mediating region of the abdominal-B locus in Drosophila. Development 126: 3057-3065.

Zhou, G.L., Xin, L., Song, W., Di, L.J., Liu, G., Wu, X.S., Liu, D.P., and Liang, C.C. 2006. Active chromatin hub of the mouse $\alpha$-globin locus forms in a transcription factory of clustered housekeeping genes. Mol. Cell. Biol. 26: 5096-5105. 


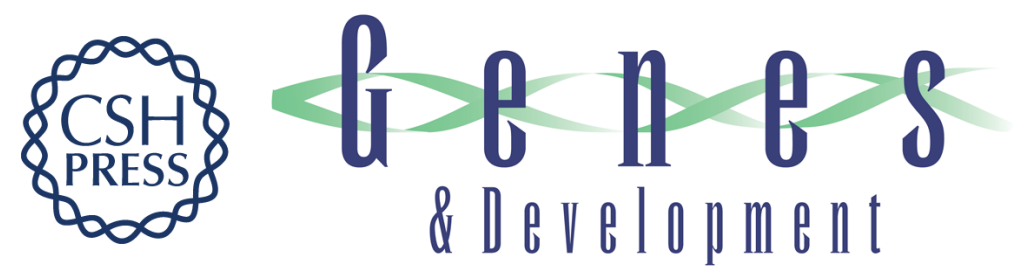

\section{Dynamics and interplay of nuclear architecture, genome organization, and gene expression}

Robert Schneider and Rudolf Grosschedl

Genes Dev. 2007, 21:

Access the most recent version at doi:10.1101/gad.1604607

References This article cites 153 articles, 49 of which can be accessed free at: http://genesdev.cshlp.org/content/21/23/3027.full.html\#ref-list-1

License

Email Alerting

Receive free email alerts when new articles cite this article - sign up in the box at the top Service right corner of the article or click here.

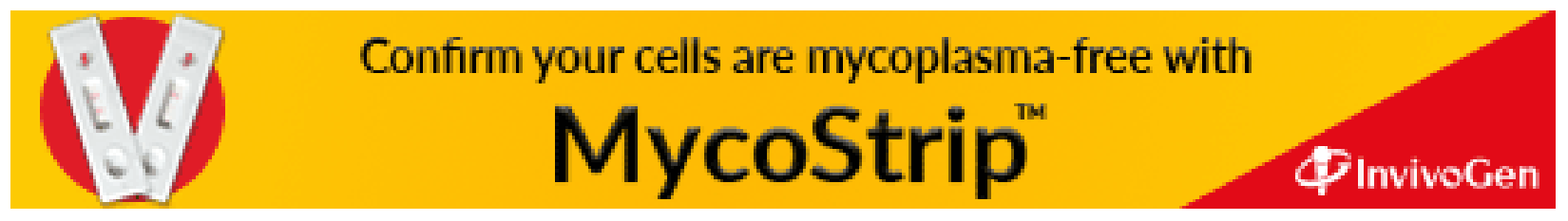

